\title{
Spectral distribution of global and diffuse solar radiation in Ny-Ålesund, Spitsbergen
}

\section{VIDAR HISDAL}

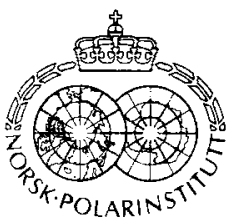

Hisdal, V. 1986: Spectral distribution of global and diffuse solar radiation in Ny-Ålesund, Spitsbergen. Polar Research 5 n.s., 1-27.

Spectral distributions of solar radiation were measured over the wavelength range 300 to $800 \mathrm{~nm}$ in $\mathrm{Ny}$-Alesund $\left(78^{\circ} 55^{\prime} \mathrm{N}, 11^{\circ} 56^{\prime} \mathrm{E}\right)$. The apparatus consisted of a grating monochromator with an automatic scanning system, an integrating sphere supposed to give a good picture of the radiation received on a horizontal surface from the whole celestial hemisphere, a photomultiplier tube with S-20 response, and a strip chart recorder. Great importance was attached to the calibration procedure, which was carried out by means of a $1000 \mathrm{~W}$ quartz-iodine lamp with known spectral irradiance (calibration traceable to NBS, delivered by Eppley Laboratory). The main part of the discussion is based on relative spectral distributions. Spectra in absolute units were obtained by comparison with simultaneous pyranometer recordings of total solar energy, which by means of filter measurements could be reduced to the same wavelength range as for the spectral scans. In addition, the pyranometer recordings served as a means of judging whether the radiation conditions were sufficiently stable to give reliable spectral curves.

Spectral measurements were made of radiation from: (1) clear sky and sun, (2) clear sky alone, a sky totally covered by (3) clouds or (4) fog, (5) zenith clear and (6) zenith overcast sky. The spectral curves of (1), (3), (4) and (6) do not differ very much, but deviate markedly from those of (2) and (5). An overcast sky has relatively higher spectral irradiances towards the short-wave end of the spectrum than the corresponding spectrum for a clear sky. Three groups of solar altitudes are considered, with mean altitudes of about $30^{\circ}$ (noon), $18^{\circ}$ (evening), and $10^{\circ}$ (night). Comparison of the spectra of these groups clearly reveals the effect of increasing absorption by atmospheric gases with decreasing solar altitude. At the same time, due to growing importance of selective scattering processes, the proportion of long-wave to short-wave irradiances increases.

The $\mathrm{Ny}$-Ålesund noon spectrum for clear-sky global radiation seems to agree quite well with spectra from lower latitudes referring to a correlated colour temperature close to $6500^{\circ} \mathrm{K}$. This also applies to the CIE standard daylight source $\mathrm{D}_{65}$. Considering the spectra in absolute units, it turns out that while the spectral irradiances of global radiation on an overcast day are about $40 \%$ of those for a clear day in the ultraviolet part, the corresponding relation decreases to about $30 \%$ in the near infrared. Sky radiation on a clear day is responsible for more than half of the ultraviolet content of global radiation, but does not contain more than about $5 \%$ of the near infrared radiation. Comparable spectra from Nottingham and Pretoria seem to be considerably more influenced by aerosol scattering. Nevertheless Pretoria has as high irradiances in the ultraviolet as $\mathrm{Ny}$-Alesund, in all probability due to a smaller ozone absorption at the former station.

A Few characteristic deductions of the spectral distributions are discussed

For situations with a clear sky daylight illuminances calculated on the basis of absolute spectral irradiances and the spectral sensitivity of the human eye agree well with directly observed illuminances for the same solar altitudes. The chromaticity co-ordinates representing different phases of daylight in Ny-Ålesund are slightly on the green side of the black body locus. Somewhat unexpected is the fact that daylight at midnight has a slightly higher correlated colour temperature (is more bluish) than that observed during the middle of the day. Estimates demonstrate the significant part played in this connection by the ozone absorption in the Chappuis bands.

Vidar Hisdal, Norsk Polarinstitutt, Rolfstangveien 12, N-1330 Oslo Lufthavn. Norway; June 1986 (revised September 1986). 


\section{Introduction}

Recordings of total direct and diffuse solar radiation received on a horizontal surface (global radiation) as well as the diffuse radiation alone (sky radiation) are included in the programme of most stations carrying out meteorological radiation measurements, and at least over some parts of the globe, we have a comparatively good knowledge of these two components of the earth's radiation budget. As to their spectral composition, however, our knowledge is far more unsatisfactory. Detailed information on this point has not been considered essential when judging the role of the short-wave radiation in the energy balance of the earth-atmosphere system. Also, the relatively complicated equipment and techniques necessary make spectral measurements unsuitable as part of a routine observation programme.

More information about the spectral characteristics of direct and diffuse solar radiation is nevertheless of considerable interest, as it is fundamental for a proper understanding of the absorption and scattering processes in the atmosphere, and thus of the selective attenuation of solar radiation. Varying content of absorbing gases, concentration and optical properties of the atmospheric aerosol, and the colour of daylight are some important aspects of this problem.

A closer study of these spectra is furthermore of importance for a series of photobiological phenomena, such as the eye's spectral response, direct tanning and erythema of the human skin, photosynthesis and other photochemical processes in plants.

Within remote sensing techniques several phenomena depend on the spectral composition of solar radiation. This applies e.g. to interpretation of narrow-band satellite imagery, even though in this case the spectral reflectance of the surface considered must be known as well. There are other more technical fields, like evaluation of the performance of solar cells, production of filters for use in photography, and the activity aiming at construction of representative artificial sources of daylight, where knowledge of the spectral composition of various phases of solar radiation is fundamental.

Only in a few cases have these spectra been studied from a geophysical point of view. Much of what we know about this subject today is in fact due to investigations made in connection with the above mentioned attempts at imitating daylight. For natural reasons, these investigations have been concerned primarily with the visual part of the spectrum, although, during later years measurements have been extended to the ultraviolet part because of the introduction of fluorescent dyes. Unfortunately, sky conditions, including solar altitude, are not very well defined in studies of this type, nor do references to meteorological conditions in general play any prominent part when the results are discussed. The aim is usually to establish some sort of 'average daylight curves', and not to evaluate the different effects responsible for characteristic features and changes of the spectra. In the following discussion we are more interested in the latter question.

\section{Factors influencing the spectral distribution}

The spectral distribution of both global solar radiation and sky radiation may be considered as an extraterrestrial solar spectrum more or less modified by various processes in the earth's atmosphere and, to some extent, by the reflecting properties of the ground. It may be useful to make a short survey of the different factors influencing the spectra:

1. Changes in extraterrestrial solar radiation.

2. Factors determining the varying attenuation effect of the atmosphere: (a) altitude of the sun, (b) optical thickness (both scattering and absorbing effects in a vertical column) for different wavelengths of a molecular atmosphere and (c) of the atmospheric aerosol, and (d) amount, distribution and types of clouds present (although strictly speaking forming part of the atmospheric aerosol, this factor should be considered separately).

3. Magnitude and spectral character of the reflectivity of the earth's surface.

4. Which part of the sky that is observed, provided the whole celestial hemisphere is not considered. 


\section{Scope and limitations of the investigation}

Evidently, the influence of the many variable factors enumerated above makes it difficult to decide which conditions are most significant for the understanding of differences between spectral distributions observed at different times or in different localities. In the present investigation we have tried, as far as possible, to keep some of the factors constant in an attempt to obtain conclusive information about the influence of the factors that change.

Three types of spectra were measured: those of global solar radiation, of sky radiation, and of radiation from the zenith sky. The measurements were made in high northern latitudes (about $79^{\circ} \mathrm{N}$ ). By comparing these spectra with each other, as well as with spectra from lower latitudes, and with spectra derived on a theoretical basis, we try to trace influences of the atmospheric aerosol (point $2 \mathrm{c}$ above) and of differences in spectral reflectance of the ground (point 3). Most of the observations are carried out at solar altitudes close to $30^{\circ}$, while a smaller part of the observation series refers to lower solar altitudes (point 2a).

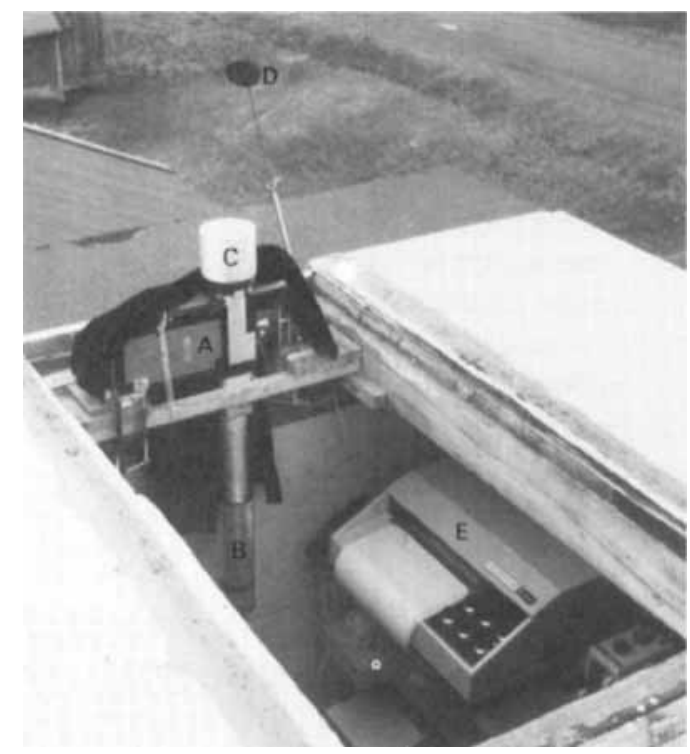

Fig. I. Monochromator and additional equipment mounted on the observation platform. A: monocromator, B: photomultiplier, $\mathrm{C}$ : integrating sphere, $\mathrm{D}$ : sun screen, E: recorder.
Considering sky conditions (point 2d), only situations with a clear sky or with a completely overcast sky are considered. In the group 'clear sky' cases with patches of clouds near the horizon are allowed. As indicated above, the spectra refer either to the whole celestial hemisphere or to the zenith sky (point 4). Effects due to variations of the extraterrestrial solar spectrum (point 1) are supposed to be small and are neglected here, whereas changes in the optical thickness of the molecular atmosphere (point 2b) may be of a certain significance as far as absorption by ozone and water vapour is concerned.

\section{Apparatus and methods of observation}

Fig. 1 shows the monochromator with additional equipment mounted on the observation platform in Ny-Ålesund.

The radiation from sun and sky was received and diffused by an intergrating sphere (Fig. 2) of a type proposed by Budde (1964), mounted in front of the entrance slit of the monochromator. The inner walls of the sphere were sprayed with several layers (total thickness about $0.5 \mathrm{~mm}$ ) of the barium-sulphate paint recommended by Middleton \& Sanders (1953), which has a comparatively high and stable reflectance over the wavelength range considered here (see also Grum \& Luckey 1968). The multiply reflected
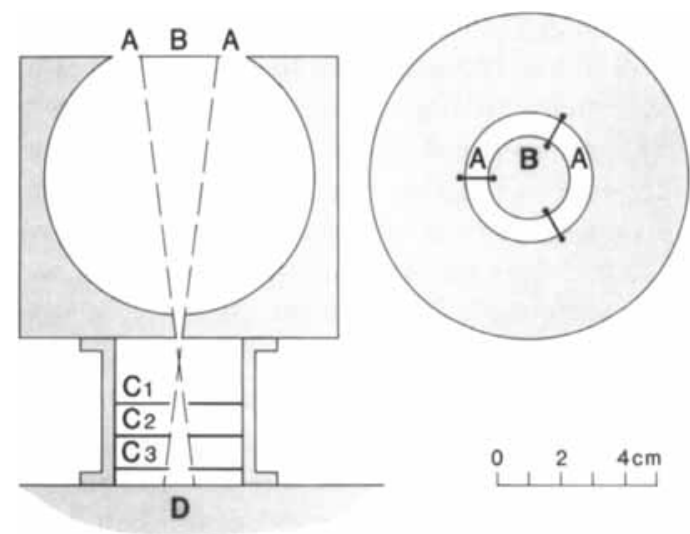

Fig. 2. Vertical cross-section of integrating sphere (left), and seen from above (right). A: ring-shaped entrance aperture, B: circular disk, C: baffles, D: monochromator. 
radiation coming from the downward facing surface of the circular disk at the top of the sphere, the only area 'seen' by the monochromator, is supposed to have a spectral distribution representative of the total radiation entering the surrounding ring-shaped aperture of the sphere. Tests carried out for different angles of incidence of the radiation entering the sphere confirmed the conclusion reached by Budde (op.cit.), that the departure from the cosine law is small and may be neglected.

A small, circular screen, mounted on a movable arm, was placed at a fixed distance from the sphere to prevent direct solar radiation from entering the sphere aperture when recording the spectrum of sky radiation alone.

To measure the zenith sky radiation a tube was attached in front of the entrance slit of the monochromator, instead of the integrating sphere. As the sky radiation is partly polarized, and the transmission of the monochromator is not independent of the characteristics of polarized radiation, it was investigated whether this fact had any marked influence on the observed zenith spectra. Therefore, a Glan polarization prism (B. Halle, Berlin) was mounted at the bottom of a second, similar entrance tube, and several series of alternating measurements were made with the two tubes. When the tube with the polarization prism was used, spectral scans were carried out with the prism axis in two directions at right angles, representing maximum and minimum transmission respectively. A system of baffles limited the angular field of view to $6^{\circ}$.

As monochromator was used a small instrument made by Hilger \& Watts (type D 292). It is easy to carry and of sturdy construction, and therefore well suited for field conditions. The dispersing element is a plane difraction grating with 576 lines per $\mathrm{mm}$, and the wavelength can be varied from 200 to $1000 \mathrm{~nm}$. To be able to scan the spectrum continuously, the monochromator was equipped with a synchronous motor which could be set at a series of different speeds. The width of the entrance and exit slits used during the measurements corresponded to a half-band width of about $3.3 \mathrm{~nm}$. In a few cases a narrower slit was used to allow a more detailed study of the spectral composition, or a wider slit to increase the instrument response in the ultraviolet and in the infrared part of the spectrum.

A Phillips type XP 100210 stage photomultiplier tube with a trialkali semitransparent cathode (response S 20) was used as detector. The photomultiplier power supply converted the DC from an $18 \mathrm{~V}$ dry battery to $\mathrm{AC}$, which was transformed to a sufficiently high voltage. After rectification, the resulting $1600 \mathrm{~V}$ output voltage was stabilized.

The monochromator with integrating sphere (or tube), motor drive, and photomultiplier with power supply were built together to one compact, transportable unit, weighing about $7 \mathrm{~kg}$.

The output current of the photomultiplier was measured by a Perkin-Elmer two-channel potentiometric stripchart recorder, with 12 ranges, the maximum sensitivity corresponding to $4 \cdot 10^{-9} \mathrm{~A} \mathrm{~mm}^{-1}$ on the chart. During most spectral scans the recorder sensitivity was changed two to three times, and the maximum chart speed of $240 \mathrm{~mm} \mathrm{~min}^{-1}$ was used.

Generally, a usable signal was obtained from 300 to $800 \mathrm{~nm}$. However, the values obtained near the start and the end of the wavelength range cannot be considered very reliable, especially in situations with low irradiance levels. To avoid disturbing influences of a second order spectrum, a Schott GG-495 filter was introduced in front of the entrance slit for wavelengths greater than $590 \mathrm{~nm}$.

The second channel of the recorder was connected to a Moll-Gorczynski pyranometer (Kipp \& Zonen), measuring global solar radiation $(300-2800 \mathrm{~nm})$, or sky radiation if direct solar rays were screened from the glass domes of the instrument. In addition, the second channel received a small voltage pulse for wavelength intervals of $50 \mathrm{~nm}$, giving marks along the curve that facilitated the reading of spectral irradiances at fixed wavelengths, which in our case meant for every $10 \mathrm{~nm}$. For a few recordings readings were made at shorter intervals to establish a more detailed course of the spectrum.

The recording of total irradiance simultaneously with the spectral scans served two purposes. In the first place it gave an opportunity to judge whether the radiation conditions were sufficiently stable to provide reliable spectral curves. This was of great importance in cases with an overcast sky. Even though an observati- 
on series was not initiated unless the cloud cover looked thick and uniform, quite considerable changes of total irradiance might occur in the course of relatively short time. If these changes exceeded about $3 \%$ of the mean irradiance, the measurements were discontinued. In several cases a spectral scan was repeated 10 to 20 times without 'running into' sufficiently constant conditions, till the attempts finally had to be given up as hopeless. Owing to these relatively strict requirements to the stability of the radiation conditions, it was seldom necessary to adjust the spectral readings to an average pyranometer value. Secondly, as will be shown later (Section 7), the simultaneous recording of total radiation gives a basis of estimating spectral irradiances in absolute units.

The requirement of stable radiation conditions meant that the spectrum had to be scanned as rapidly as possible. As mentioned above this was especially important during situations with an overcast sky. The measuring system, on the other hand, needs a certain minimum time to record with sufficient accuracy fast changes of the received signal. Experiments showed that a scanning time of 3 minutes for the range $300-800$ $\mathrm{nm}$ seemed adequate. This meant that with the recorder set at maximum chart speed, $10 \mathrm{~nm}$ corresponded to $16 \mathrm{~mm}$ on the chart.

To correct to some extent for slight lags that might still be present in the measuring system, or for long term trends due to changing altitude of the sun or a slowly varying transparency of a cloud cover, a scan starting at one end of the spectrum was always immediately repeated in the reverse direction, and the two series were averaged. The differences between the two series were in most cases insignificant.

\section{Site and period of observation}

The apparatus was mounted on a platform below the topmost part of the roof of a two storey building in $\mathrm{Ny}$-Ålesund, a former Norwegian colliery at $78^{\circ} 55^{\prime} \mathrm{N}, 11^{\circ} 56^{\prime} \mathrm{E}$ (see Figs. 1 and 3 ). When removing a hatch protecting the instruments, the integrating sphere was freely exposed, and there were no adjacent obstacles shielding the horizon. As seen from the observatory platform, the top of Zeppelinfjellet towards SSW had the largest angular altitude, $13^{\circ}$. A few other isolated peaks in the southerly sector had altitudes about $10^{\circ}$. The same applied to Scheteligfjellet to the west $\left(9^{\circ}\right)$. The major part of the geographic horizon, however, lay well below $5^{\circ}$. In the following discussion we assume that possible distortions of the observed spectra due to shadowing effects or reflection from the mountains may be neglected.

The observation site was situated $14 \mathrm{~m}$ above sea level and about $300 \mathrm{~m}$ from the shore. In addition to plains covered by coal residuals, sand and stone, sparse tundra vegetation and varying amounts of snow, the environment consists of glaciers and partly snow-free mountains. The extent of the snow cover in the lowland surrounding the station varied considerably from year to year, and might decrease from, say, $70 \%$ to nearly $0 \%$ in the course of an observation period. Also, especially early in the season, the fiord might have an extensive ice cover.

The measurements were carried out during the months June to August in the years $1970-72-73-74$.

\section{Calibration}

It was too complicated to carry out sufficiently precise calibration of the apparatus in $\mathrm{Ny}$ Alesund. This had to be done before the departure from Oslo and after the return home. It was therefore decided to determine the spectral response of the measuring system in relative units only. As far as possible, the conditions during the calibration procedure were so arranged as to resemble closely those existing when the observations were made.

\subsection{Dark current and stray light}

The dark current of the photomultiplier tube used is small, and was corrected for by frequent checking of the zero-point of the recorder when no radiation entered the monochromator.

A more difficult task was that of finding a reliable correction for the influence of scattered radiation (stray light) in the monochromator, which caused a comparatively low 'signal to noise ratio' near the short-wave and long-wave limits of the spectrum. The variation of this effect 
was estimated by reading the output signal of the photomultiplier tube for a series of wavelengths when different "cut-off filters were placed in front of the entrance slit, and an estimate of the magnitude of the effect was obtained by measuring the signal for wavelengths for which the photomultiplier should no longer be sensitive, or for which the radiation source did not emit energy. To be able to correct for stray light, therefore, a spectral scan was always started at $280 \mathrm{~nm}$ (no measurable solar radiation, negligible or no photomultiplier sensitivity) and ended at $900 \mathrm{~nm}$ (no photomultiplier sensitivity).

Except for minor fluctuations, the relative influence of stray light decreased with increasing wavelength, and was furthermore considerably reduced when introducing the GG-495 filter at $590 \mathrm{~nm}$. For spectral measurements of global solar radiation the stray light effect was responsible for around $40 \%$ of the signal recorded at $300 \mathrm{~nm}$. However, its influence decreased rapidly, and was only about $5 \%$ at $320 \mathrm{~nm}$. In the range $390-700 \mathrm{~nm}$ it was generally well below $1 \%$, and then increased gradually to about $15 \%$ at $800 \mathrm{~nm}$. In the case of sky radiation, which has a relatively much stronger irradiance in the ultraviolet and blue part of the spectrum, the corresponding percentages were only about half as great near the ultraviolet end, but nearly twice as great when approaching the $800 \mathrm{~nm}$ limit.

\subsection{Wavelength}

The wavelength scale of the monochromator was checked from time to time by a set of narrowband interference filters, or by the principal

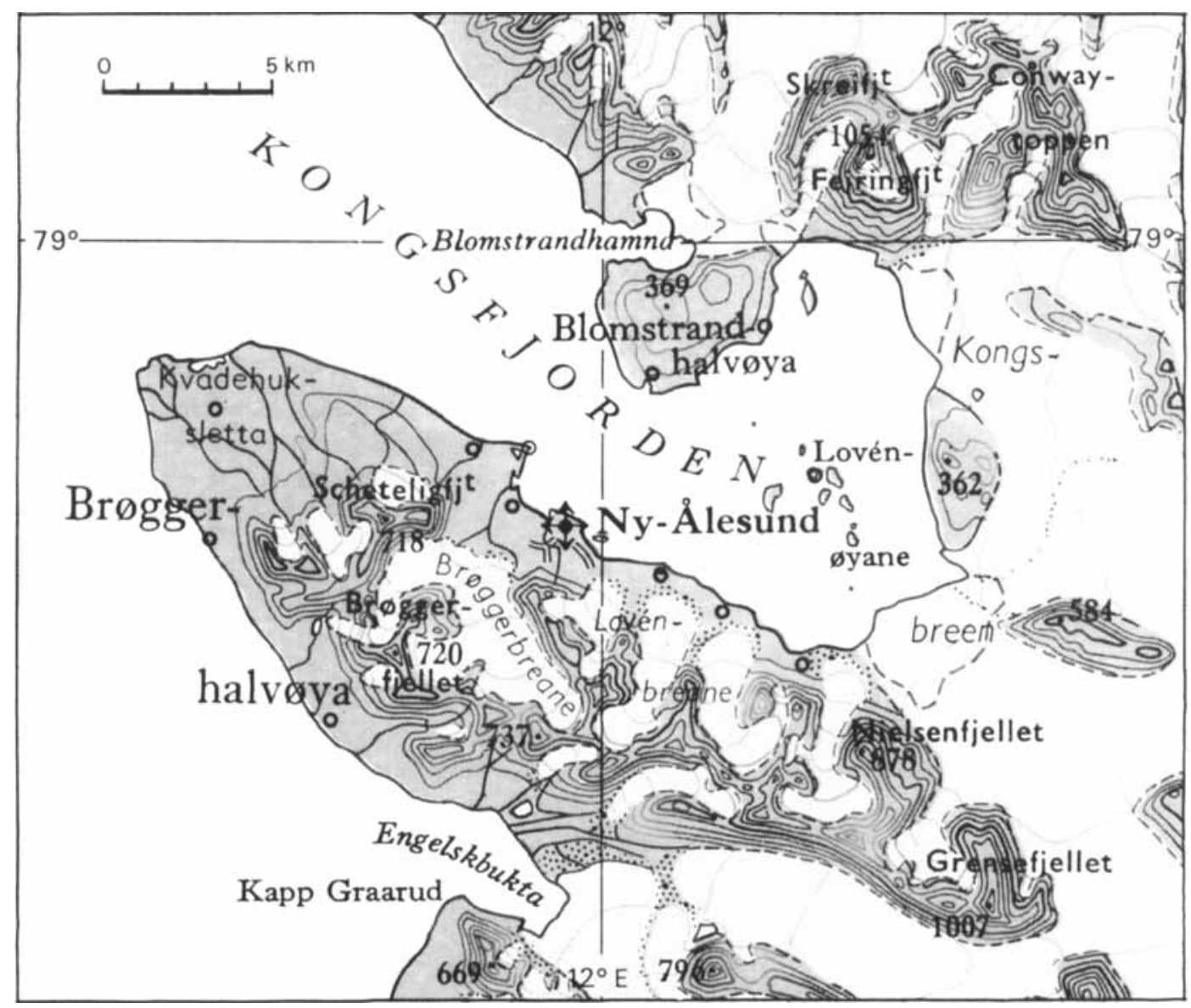

Fig. 3. Ny-Ålesund and surrounding areas. 
emission lines of a $\mathrm{Hg}$-Cd-Zn-lamp. In $\mathrm{Ny}$ Ålesund the postion of characteristic absorption bands in the observed spectra served as a good indicator that no displacements had occurred in the monochromator during the long and often not too gentle transport to Svalbard. It was never found necessary to readjust the instrument because of changes in the wavelength scale.

\subsection{Radiation source}

As standard source of spectral irradiance was used a $1000 \mathrm{~W}$ tungsten-filament quartz-iodine lamp, calibrated at a filament current of $8.30 \mathrm{~A}$ for the range $250 \mathrm{~nm}$ to $2500 \mathrm{~nm}$ at the Eppley Laboratory. This calibration is based on comparisons with NBS standards (Schneider et al. 1968). Two lamps of the same type (General Electric, Type DXW) served as working standards, and were checked against the Eppley standard at regular intervals. The relationship between the spectral irradiance of the lamps proved to be practically constant during the whole observation period. At the end of this period the working standard most frequently applied had a total burning time of 59 hours.

The lamp in its special Eppley holder was mounted in a comparatively large lamphouse $(30 \times 50 \times 45 \mathrm{~cm})$ with double blackened walls, the whole system being cooled by a turbo-fan. The radiant flux from the lamp could only escape through a $2 \mathrm{~cm}$ wide and $12 \mathrm{~cm}$ high slit in the front of the lamp house.

The current operating the lamp was stabilized by a Sorensen electronic AC line regulator, giving a constant output voltage of $220 \mathrm{~V}$ (accuracy $\pm 0.1 \%$ ). The regulator was connected to a Phillips variable autotransformer, the output current of which went through a second transformer delivering the $120 \mathrm{~V} \mathrm{AC}$ required by the lamp. The lamp filament current was measured by a Norma precision amperemeter (class 0.2 ). The electrical circuit outlined here made it possible to keep this current very precise and stable on the prescribed value of $8.30 \mathrm{~A}$ throughout the calibration procedure.

\subsection{Radiation entering the monochromator}

When calibrating the measuring apparatus with the integrating sphere at the entrance slit of the monochromator, the lamp flux entered directly through the ring-formed aperture and was diffusely reflected by the barium sulphate coating of the sphere wall. For the monochromator equipped with an entrance tube during zenith measurements a somewhat more complicated procedure was necessary. The radiant flux from the lamp was reflected into the entrance tube by a $5 \mathrm{~mm}$ thick tablet of barium sulphate powder (Eastman white reflectance powder) covering the whole angular field of view of the instrument. These tablets, which were pressed into a sample holder by means of a special equipment made by Zeiss, have proved to have excellent properties as white standards (Richter \& Terstiege 1970). They were from one day to a few weeks old when the calibration took place. Comparisons made between new and up to two year old tablets showed that the spectral reflectance of this pressed powder was very stable. Only a slight deterioration of the reflectance in the ultraviolet could be observed with certainty. This is in agreement with results obtained by Grum \& Luckey (1968). Their investigation furthermore showed that the spectral reflectance is practically constant in the wavelength range here considered. We have corrected for a small reduction of reflectance in the $300-400 \mathrm{~nm}$ region (up to $2 \%$ ), based on the data published in the work referred to.

\subsection{Polarization effects}

In accordance with investigations published by Kaase (1973), tests with a polarimeter showed that radiation received from the integrating sphere as well as that reflected from the $\mathrm{BaSO}_{4}$ tablets may be considered as unpolarized.

For the observations made with the polarization prism described previously, two series of calibration factors were needed, one for each of the two positions of the prism. If the numbers 1 and 2 indicate the two prism positions, the two components of the zenith radiation may be written $\mathrm{z}_{1}$ and $\mathrm{z}_{2}$ (wavelength index omitted), producing photomultiplier signals $s_{\mathrm{z} 1}$ and $s_{\mathrm{z} 2}$. If the corresponding calibration factors are $c_{z 1}$ and $\mathrm{c}_{\mathrm{z} 2}$, the total (monochromatic) zenith irradiance becomes:

$\mathrm{z}=\mathrm{z}_{1}+\mathrm{z} 2_{2}=\mathrm{c}_{\mathrm{z} 1} \mathrm{~s}_{\mathrm{z} 1}+\mathrm{c}_{\mathrm{z} 2} \mathrm{~s}_{\mathrm{z} 2}$ 
The zenith spectra obtained in this way were, however, very nearly the same as those observed simultaneously without a polarization prism. It was concluded, therefore, that also in the case of zenith radiation from a clear sky the influence of the polarization effect on the measurements could be disregarded.

\subsection{Results}

As a result only two series of calibration factors were needed:

$c_{i}$ when using the integrating sphere,

$c_{2}$ when using the entrance tube (without polarization prism).

Fig. 4 shows the variation with wavelength of relative $c_{i}$ values for 1970 and 1974 ( $c_{i}$ put equal to 1 for $560 \mathrm{~nm}$ ). The large variation of the factor from about 0.4 in the $400 \mathrm{~nm}$ region to more than 60 at $800 \mathrm{~nm}$, is primarily due to the strong wavelength-dependent sensitivity of the photocathode material. Also, the variation with wavelength of the reflectance of the inner surface of the integrating sphere and particularly the spectral characteristics of the transmission factor of the monochromator are of importance. Thus, the latter effect is no doubt responsible for the secondary maxima of the calibration curves. They are found in the same wavelength regions when using other types of photomultipliers as sensors, and are presumably due to optical properties of the grating.

The change of the calibration factor from 1970 to 1974 is comparatively moderate. Apart from $3-4$ values near each end of the spectrum, this change does not exceed $10 \%$, and is generally much smaller, even far from the common crossing point at $560 \mathrm{~nm}$. The calibration curves further show that the apparatus in the course of time has become less sensitive in the short-wave region relative to the long-wave region.

Considering the calibration factor $c_{2}$, when using a tube instead of integrating sphere before the entrance slit, the general course of the calibration curves is the same as that of $c_{\text {. }}$. Putting the two factors equal at $560 \mathrm{~nm}$, they are not very different for wavelengths above, say, $500 \mathrm{~nm}$. However, $c_{z}$ gets gradually much smaller than $c_{i}$ towards the ultraviolet and is only about $40 \%$ of $c_{i}$ at $300 \mathrm{~nm}$. Also the change of $c_{z}$ from 1970 to 1974 is definitely smaller than that shown for $c_{i}$ in Fig. 4. In all probability these differences are mainly caused by a decrease in the reflectance of the sphere paint towards the short-wave end of the spectrum, and by the fact that this decreasing reflectance has become somewhat more marked in the course of the observation period. (The $\mathrm{BaSO}_{4}$ cover was not renewed during this period.) These effects are considerably increased by multiple reflection within the sphere.

Estimates of $c_{i}$ and $c_{z}$, representative of the individual observation periods, are obtained by linear interpolation.

\subsection{Comparisons}

To obtain a check of the accuracy of the whole measuring system, it was compared, before starting the observation program, with another equipment for spectral measurements at the Central Institute of Industrial Research (Oslo). The dispersion unit of the latter apparatus was a Zeiss double-prism monochromator (Type PMQ2). The comparison was carried out by using both systems to establish the spectral composition of the radiation from a $800 \mathrm{~W}$ quartziodine lamp, applying a ribbon filament standard lamp of spectral radiance with quartz window (Eppley Laboratory), operated at a filament current of $35.0 \mathrm{~A}$, as reference source. In view of the smooth course of the spectral distribution considered, the increasing half-band width with wavelength of the prism monochromator (from $1.5 \mathrm{~nm}$ to $15 \mathrm{~nm}$ in this case) was assumed to be of small importance. Putting the relative spectral irradiances equal at $560 \mathrm{~nm}$, as is usually done when comparing spectral measurements of 'daylight', the maximum difference between the two lamp spectra obtained was $3.5 \%$ (at $700 \mathrm{~nm}$ ). In addition, the differences were of fairly unsystematic character, being no doubt to a large extent due to 'random disturbances', and the result of the test was on the whole considered satisfactory.

\section{Pyranometer measurements}

As mentioned previously, recordings of total solar irradiance by a Moll-Gorczynski pyranometer should indicate whether the radiation 
Fig. 4. Variation with wavelength of the relative calibration factor (G put equal to 1 for $560 \mathrm{~nm}$ ) when using the integrating sphere in 1970 and 1974.

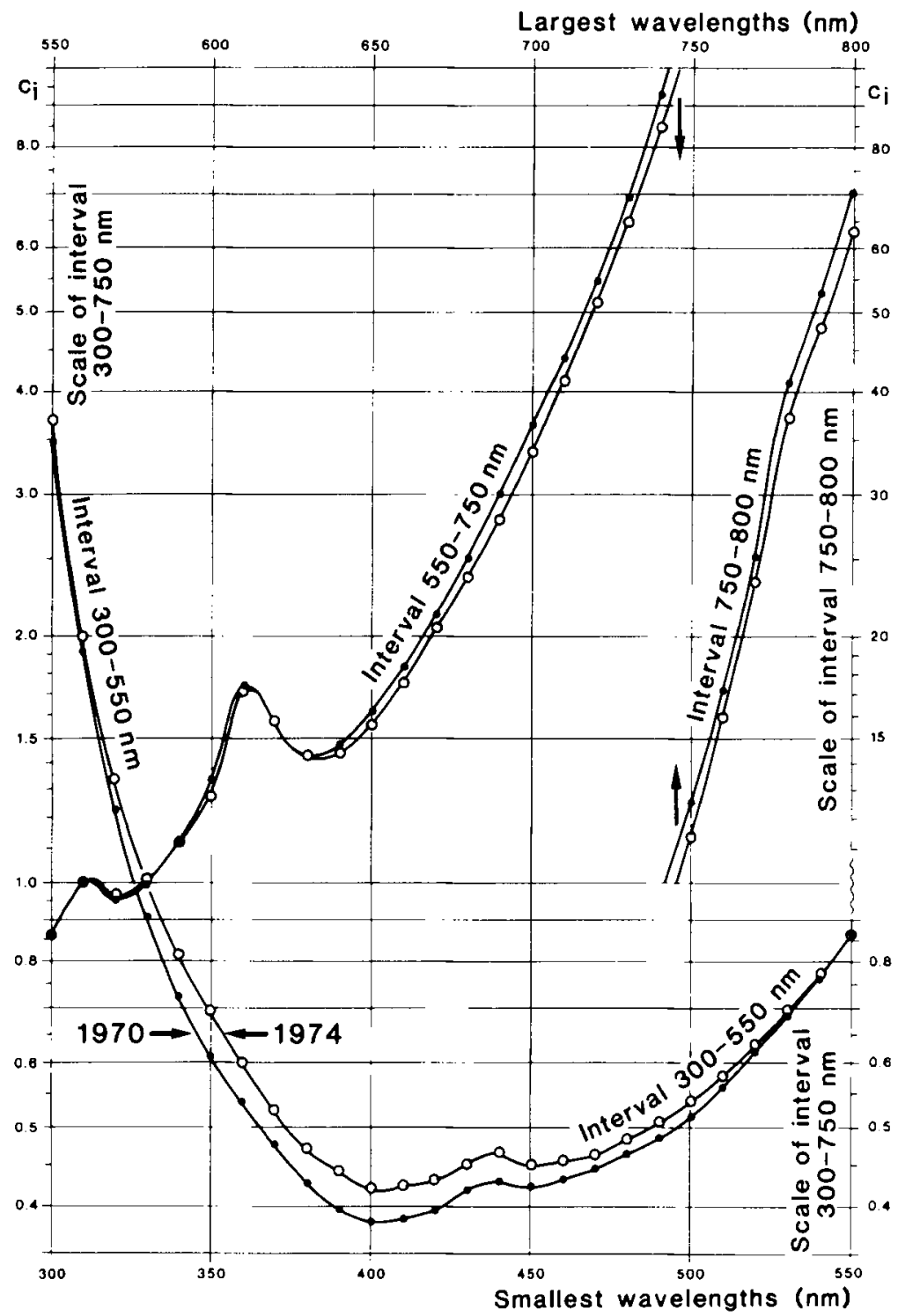

conditions were sufficiently stable for spectral measurements, and provide a basis for an attempt to estimate spectral irradiances in absolute units.

The calibration factor of the instrument was checked by comparison with two other pyranometers, one of the Moll-Gorczynski and one of the Eppley type, mounted at the Research Station, about $150 \mathrm{~m}$ from our own measuring site. These latter instruments measured continuously global solar radiation and sky radiation, and were calibrated each summer by means of an Angström pyrheliometer. The calibration factor of all three instruments proved to be practically constant during the observation period considered here (T. Vinje, pers. comm.).

To use pyranometer readings as a basis of estimating spectral irradiances in absolute units, it is necessary to have the ratio of the total radiation given by the pyranometer and the part of this total radiation that is contained in the wavelength range considered during the spectral in- 
Fig. 5. Alternating pyranometer recordings with Schott WG-295 and RG-695 hemispherical filters of global solar radiation (upper part) and with direct sun rays screened off (lower part).
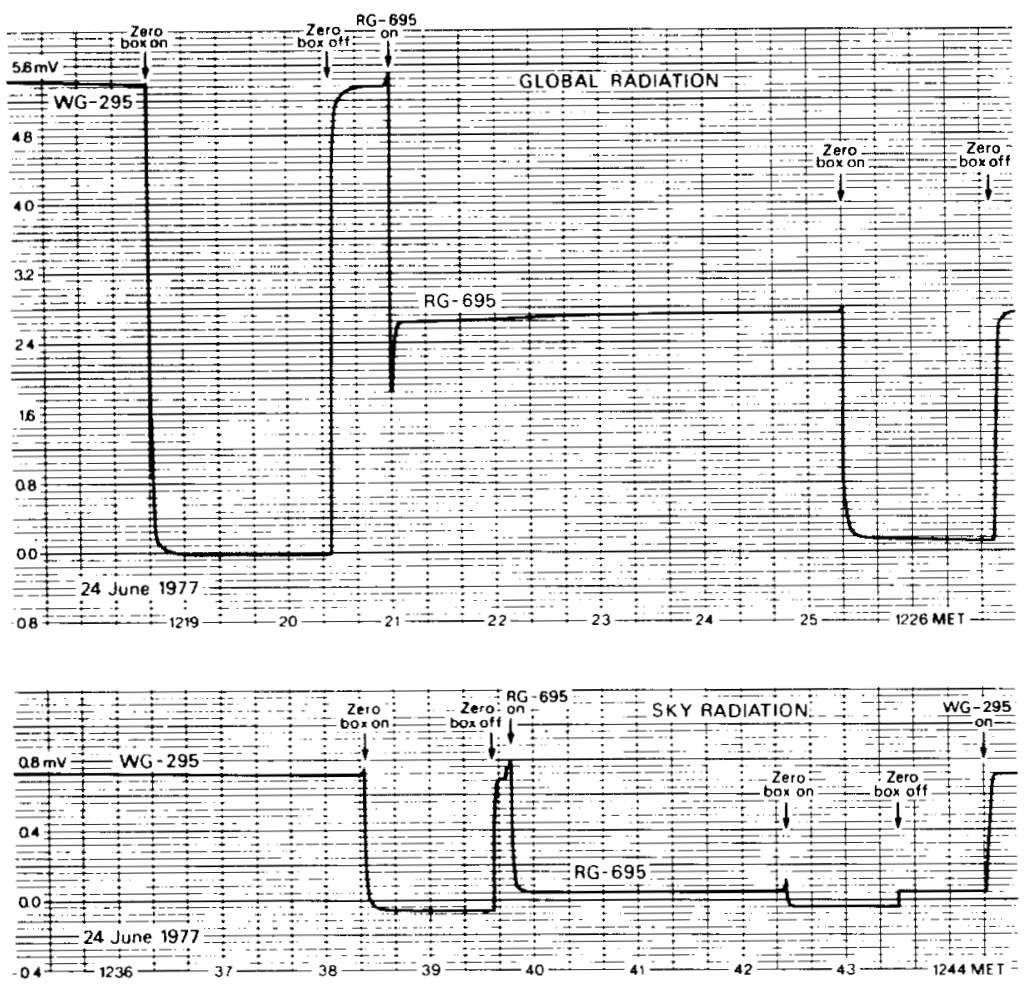

vestigation (or within a certain part of this wavelength range). This relation was measured during the summer seasons $1976-77$ by means of an Eppley pyranometer equipped with Schott WG-295 glass hemispheres for measuring total short-wave radiation (global or sky radiation), and a Schott RG-695 outer glass hemisphere for measuring total solar radiation for wavelengths exceeding $700 \mathrm{~nm}$.

During the measurements one type of outer glass hemispheres was mounted on the pyranometer for a few minutes, and then quickly replaced by one of the other type. This procedure was repeated several times, and the output voltage of the pyranometer was measured continuously by a strip-chart recorder. As an example two sections of a recording made at noon with clear sky are shown in Fig. 5.

As is clearly apparent in the diagram, there may be a considerable difference between the registration curve when the short wave radiation is cut off by placing a box over the glass hemispheres and the electrical zero line. It is especial- ly important to be aware of this zero-point deviation when making comparative filter measurements of different parts of the spectrum. A discussion of the problem is published elsewhere (Hisdal 1980). We therefore confine ourselves to say that the measurements discussed below may, to a good approximation, be supposed to be corrected for the zero-point deviation.

Table I shows some main results of the pyranometer observations made near noon. We consider the relation, q, between the total short-wave irradiance and the part of it that is contained in the wavelength range below $700 \mathrm{~nm}$. As would be expected, $\mathrm{q}$ is smallest for clear sky radiation, where almost all energy is contained in the ultraviolet and visible part of the spectrum. Also, the value of $\mathrm{q}$ for an overcast sky is considerably smaller than the corresponding value for a clear sky and sun, which may partly be due to a greater water vapour and hydrometer absorption in the infrared during overcast situations. For the latter situations $\mathrm{q}$ is also most variable, the extreme values deviating about $3.5 \%$ from the mean. 
Table 1. The ratio (q) of the total solar irradiance to that contained in the wavelength interval $300-700 \mathrm{~nm}$. Observations taken in $\mathrm{Ny}$-Ålesund during the middle of day in May-June 1976-77.

\begin{tabular}{|c|c|c|c|c|c|}
\hline $\begin{array}{l}\text { Radiation } \\
\text { source }\end{array}$ & $\begin{array}{l}\text { Num } \\
\text { days }\end{array}$ & $\begin{array}{l}\text { ber of } \\
\text { obs. }\end{array}$ & $\begin{array}{c}\text { Mean rel. } \\
\text { air mass }\end{array}$ & $\begin{array}{c}q \\
\text { range }\end{array}$ & $\underset{\text { mean }}{q}$ \\
\hline $\begin{array}{l}\text { Clear sky } \\
\text { and sun }\end{array}$ & 10 & 2 & & -1.98 & 1.937 \\
\hline $\begin{array}{l}\text { ly } \\
\text { vercast }\end{array}$ & 4 & 12 & 1.89 & $1.11-1.17$ & 137 \\
\hline & 3 & 15 & 1.83 & $1.55-1.66$ & 1.602 \\
\hline
\end{tabular}

The variation of q may to some extent be attributed to variation in solar altitude. If we, in addition to the tabulated noon observations, take into account evening and night observations for the following types of radiation sources:(I) Clear sky and sun, (II) Clear sky only, and (III) Overcast sky, we obtain the following regression equations and correlation coefficients between $q$ and the relative air mass $M$ :

$\begin{array}{lll}\text { I } & \mathrm{q}=0.039 \mathrm{M}+1.860 & \mathrm{r}=0.86 \\ \text { II } & \mathrm{q}=0.026 \mathrm{M}+1.090 & \mathrm{r}=0.83 \\ \text { III } & \mathrm{q}=0.033 \mathrm{M}+1.536 & \mathrm{r}=0.69\end{array}$

It appears that $q$ increases slightly with increasing $\mathrm{M}$, which indicates a dominating influence of the scattering effect, causing a relatively stronger reduction of the irradiance towards the ultraviolet part of the spectrum.

It is assumed that fairly good estimates of average $q$ values for the periods when the spectral measurements were made are obtained from the above equations by putting $\mathbf{M}$ equal to the mean air mass for the different groups of spectra.

The relative global radiation (or sky radiation), $K_{r}$, may now be estimated in the same units as those applied for the spectral investigations:

$\mathrm{K}_{\mathrm{r}}=\mathrm{qK}_{\mathrm{r}}^{\prime}$

where $K_{r}^{\prime}$ is the part of the global radiation contained in the wavelength interval below $700 \mathrm{~nm}$. Spectral irradiances in absolute units, $I_{a \lambda}$, may then be calculated from the corresponding relative values, $\mathrm{I}_{\mathrm{r} \lambda}$, by the expression:

$$
\mathrm{I}_{\mathrm{a} \lambda}=\mathrm{I}_{\mathrm{r} \lambda} \frac{\mathrm{K}_{\mathrm{a}}}{\mathrm{K}_{\mathrm{r}}}
$$

Here $K_{a}$ is the average global (or sky) radiation measured with the pyranometer simultaneously with the spectral scans.

\section{Discussion of the spectral distributions}

Table 2 gives a survey of the number of days of observation, mean relative air mass (Bemporad's values), and corresponding true solar altitudes for the different types of spectra. Evidently the expression 'noon' in the table is not used in the strict sense of the word. In the present discussion it simply means that the measurements are made at solar altitudes ranging from $25^{\circ}$ to the maximum altitude of $34.5^{\circ}$. Correspondingly, evening and night spectra are measured at solar altitudes between $15^{\circ}$ and $25^{\circ}$, and between $7^{\circ}$ and $15^{\circ}$ respectively. A few evening and night spectra will not be discussed and are not specified in the table, namely those of global radiation in fog situations and of zenith radiation for an overcast sky. The modest number of spectra of these types do not show any essential features that are not revealed when discussing the rest of the data.

In the following we consider average courses of groups of spectra belonging to the same type. It should be stressed, however, that the course of the individual spectra within one and the same group shows no great dissimilarities. This applies particularly to situations with a clear sky. Thus, for global radiation at noon the range of relative irradiances at 400 and $700 \mathrm{~nm}$, for instance, does not exceed $\pm 5 \%$ of the mean value.

Spectra of direct solar radiation will not be studied. They had to be estimated as differences between simultaneous absolute spectra of global radiation and sky radiation respectively, which in themselves are somewhat uncertain. It seems questionable, therefore, whether sun spectra estimated in this way would be sufficiently reliable to give conclusive results. 
Table 2. Specification of the observation material.

\begin{tabular}{|c|c|c|c|c|c|c|}
\hline \multirow[b]{2}{*}{ Type of radiation } & & \multirow{2}{*}{$\begin{array}{l}\text { Time } \\
\text { of day }\end{array}$} & \multicolumn{2}{|c|}{ Relative air mass } & \multirow{2}{*}{$\begin{array}{l}\text { Mean solar } \\
\text { altitude }\end{array}$} & \multirow{2}{*}{$\begin{array}{c}\text { Number } \\
\text { of days }\end{array}$} \\
\hline & & & Range & Mean & & \\
\hline \multicolumn{7}{|l|}{ Global radiation } \\
\hline \multirow[t]{3}{*}{ Clear sky } & A & Noon & $2.16-1.79$ & 1.97 & $30.5^{\circ}$ & 16 \\
\hline & B & Evening & $3.79-2.61$ & 3.16 & $18.3^{\circ}$ & 7 \\
\hline & $\mathrm{C}$ & Night & $7.39-4.47$ & 5.50 & $10.1^{\circ}$ & 7 \\
\hline \multirow[t]{3}{*}{ Overcast } & $\mathrm{D}$ & Noon & $2.25-1.78$ & 1.95 & $30.7^{\circ}$ & 24 \\
\hline & E & Evening & $3.11-2.79$ & 2.95 & $19.7^{\circ}$ & 3 \\
\hline & $F$ & Night & $5.60-4.54$ & 4.95 & $11.3^{\circ}$ & 4 \\
\hline Fog & $\mathrm{G}$ & Noon & $2.01-1.94$ & 1.97 & $30.5^{\circ}$ & 2 \\
\hline \multicolumn{7}{|l|}{ Sky radiation } \\
\hline \multirow[t]{3}{*}{ Clearsky } & $\mathrm{H}$ & Noon & $2.10-1.81$ & 1.96 & $30.6^{\circ}$ & 9 \\
\hline & I & Evening & $3.79-2.54$ & 3.26 & $17.7^{\circ}$ & 5 \\
\hline & $\mathrm{J}$ & Night & $7.48-4.47$ & 5.65 & $9.8^{\circ}$ & 5 \\
\hline \multicolumn{7}{|l|}{ Zenith radiation } \\
\hline \multirow{3}{*}{ Clearsky } & K & Noon & $2.08-1.82$ & 1.98 & $30.3^{\circ}$ & 11 \\
\hline & $\mathrm{L}$ & Evening & $3.53-2.68$ & 3.21 & $18.0^{\circ}$ & 5 \\
\hline & M & Night & $7.87-4.54$ & 5.71 & $9.7^{\circ}$ & 4 \\
\hline Overcast & $\mathrm{N}$ & Noon & $2.33-1.79$ & 2.03 & $29.4^{\circ}$ & 10 \\
\hline
\end{tabular}

Number of days with observations of both

$A$ and $B: 3 \quad A$ and $C: 3 \quad H$ and $I: 3 \quad H$ and $J: 3$

Number of days with simultaneous observations of
$\mathrm{A}$ and $\mathrm{H}: 9$
$B$ and $I: 5$
$\mathrm{C}$ and $\mathrm{J}: 5$
D and N: 10
$H$ and $K: 8 \quad I$ and $L: 3 \quad J$ and $M: 4$

\subsection{Noon Spectra}

The various types of average noon spectra are shown in Fig. 6. The irradiances are normalized by expressing them as per cent of their value at $560 \mathrm{~nm}$. The data thus give information primarily about the form and structure of the individual spectral distributions.

As would be expected, there is a marked difference between the course of the distribution of clear sky radiation from zenith as well as the whole hemisphere on the one hand, and the distribution of different types of global radiation and zenith radiation from an overcast sky on the other. Thus, if we compare the spectrum of sky radiation and global radiation for a clear sky, we find that in relation to the value at $560 \mathrm{~nm}$ the spectral irradiance of sky radiation at $350 \mathrm{~nm}$ is 4 times as large as that of global radiation, while at $750 \mathrm{~nm}$ the corresponding ratio is 0.4 .

Regarding the zenith sky spectra observed in Ny-Ålesund in 1966 (Hisdal 1969), they deviate to some extent from those discussed here. This applies especially to the clear-sky spectra, where the new spectral distribution is about $10 \%$ lower in the shortwave region (say, below $420 \mathrm{~nm}$ ) and correspondingly higher for the longest wavelengths. These deviations are supposed to be mainly due to the better measuring and calibration technique applied in the present case.

The three types of global radiation (clear sky, overcast, fog) have nearly the same spectral composition. An overcast sky has somewhat higher irradiances towards shorter wavelengths. This seems to be a typical feature, as it is clearly in evidence even if the individual years are considered separately, and it agrees well with results found previously, that daylight under an overcast sky is slightly more blue than that under a clear 


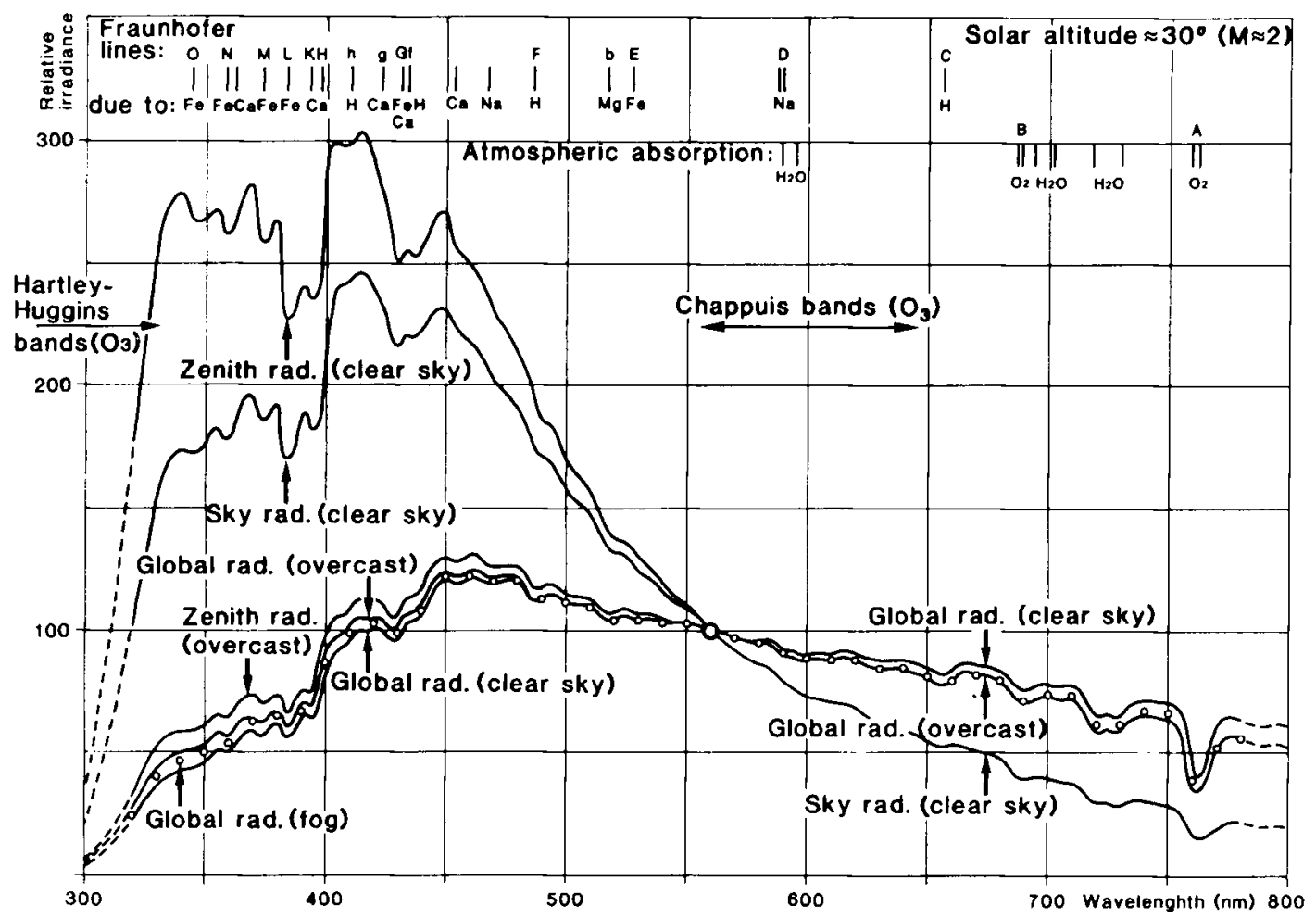

Fig. 6. Various types of average noon spectra expressed in relative units (equal to 100 at $560 \mathrm{~nm}$ ). Above $560 \mathrm{~nm}$ the curves for Zenith (clear sky) and Zenith (overcast) are omitted. They nun below, but very close to the curves for Sky radiation (clear sky) and Global radiation (overcast) respectively. The spectrum representing fog situations is indicated by small rings.

sky (Walsh 1961). Presumably several factors contribute to this fact. The albedo as well as transmissivity of a cloud layer are selective processes and leave their traces in the spectra observed at the ground. However, our knowledge about these processes is too scanty to allow an evaluation of the final spectral attenuation effect. As is usually the case in Arctic regions, situations with a dense and even overcast are at the same time distinguished by a very low cloud base, in most cases only a few hundred metres (stratus or stratocumulus). It is doubtful, therefore, whether the effect mentioned by Hunt (1975) is of any great importance, viz. that a high cloud layer can catch much of the 'blue' radiation scattered in the atmosphere below, before it is lost to space, and reflect it back to the ground.

Considering the fog, it was of the shallow, Arctic type, and the sky above the fog layer was totally or partly clear, giving a blue hue to the zenith sky. It seems reasonable, therefore, that the fog spectrum takes an intermediate course between that of an overcast and that of a clear sky.

The irregular course of the spectral curves shows that the resolution of the monochromator (half-band width: $3.3 \mathrm{~nm}$ ) is sufficient to reveal a long series of absorption lines and bands. The positions of some of the strongest solar Fraunhofer lines and atmospheric absorption bands are entered in the upper part of Fig. 6. These positions agree well with those of the more or less pronounced dips in the spectral curves. Regarding the solar lines, the most marked influences are those of the $\mathrm{Fe}$ - and $\mathrm{Ca}$-lines in the $380-400 \mathrm{~nm}$ and $420-440 \mathrm{~nm}$ regions. Also, atmospheric absorption by water vapour and oxygen has left clear traces in the curves, such 
as the dip between 710 and $740 \mathrm{~nm}\left(\mathrm{H}_{2} \mathrm{O}\right)$ and the pronounced minimum near $760 \mathrm{~nm}$ due to $\mathrm{O}_{2}$-absorption.

As pointed out previously, when discussing the measuring equipment, the 'signal to noise ratio' was low near the short-wave and long-wave ends of the spectra, and the values here (indicated by broken curves in the diagram) cannot be considered well established. Thus, the comparatively large values at the ultraviolet end of the spectra may be due to an inadequate correction of the measurements.

\subsection{Influence of solar altitude}

In Fig. 7 is illustrated the variation with wavelength of the relation between evening and noon spectra, and between night and noon spectra. Again we have confined ourselves to normalized spectra, which means that all relationships are equal to unity at $560 \mathrm{~nm}$. Of course, since radiation intensities, other things being equal, are highest at noon, the relations in the diagram would have been smaller if they were based on absolute spectral irradiances. This would, however, only mean linear changes of the individual ordinate scales. The relations between the zenith-sky spectra are omitted, since their variation with wavelength is much the same as that of the corresponding sky-radiation spectra for the whole hemisphere.

To obtain as unambiguous data as possible we consider the relations only between sets of spectra that have been observed on the same day, even though this means a marked reduction of the number of observations (see Table 2). It may be added that the corresponding relations based

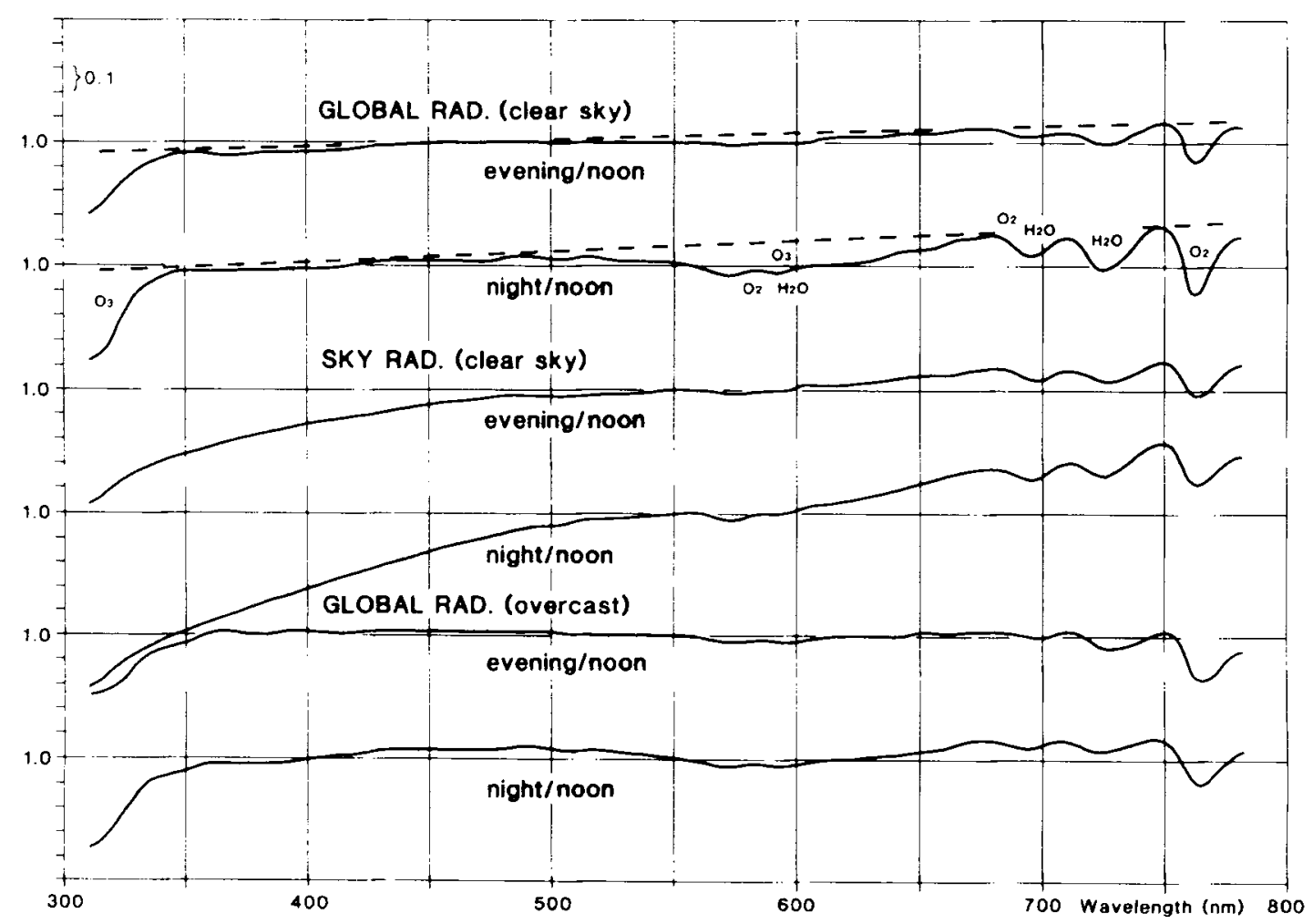

Fig. 7. Variation with wavelength of the relation between evening and noon spectra, and between night and noon spectra. Relative units (see Fig. 6). 
on the total number of observations show no marked deviations from those given in Fig. 7.

As is clearly apparent in the diagram, the lower the sun the more marked are the minima due to atmospheric absorption. This also means that the slight ozone absorption at the standard wavelength $560 \mathrm{~nm}$ (Chappuis bands) causes the curves to be shifted upwards as the path of the solar rays through the atmosphere increases.

The curves in Fig. 7 furthermore show how the proportion of long-wave to short-wave irradiances increases with decreasing solar altitude. The reason for this tendency is obviously the increasing influence of the selective scattering processes when the path of the solar rays increases. This gives relatively lower spectral irradiances towards the short-wave end of the spectrum, not only in the case of global radiation (clear sky), but even more so in the case of diffuse sky radiation. For global radiation the trend seems to be practically linear in the wavelength range considered here, as indicated by the broken lines in the diagram. It may seem unexpected that this 'red-shift' with decreasing solar altitude is less marked for global radiation. It is no doubt due to a considerably larger influence of 'blue' sky radiation on the composition of global radiation when the sun is low.

For situations with overcast sky only the course of the night-noon quotients reveals a faint influence of the selective scattering effect. One main reason for this fact is in all probalility that the cloud top albedo for direct solar radiation increases when the sun's altitude decreases (Wiscombe 1973). Accordingly the influence of the spectral composition of direct solar radiation on the spectrum observed at the ground is correspondingly reduced, and that of sky radiation increased.

We shall return later to some consequences of these changes of the spectra with solar altitude, particularly for the colour of a clear sky and of daylight in general.

\subsection{Relation between different types of spectra}

Fig. 8 illustrates how the relation between different types of spectra varies with wavelength. Except for the comparison between clear and over- cast days, all relations are based on sets of spectra that are observed practically simultaneously. As in the preceding section, the reason for reducing the number of observation series in this way is to obtain a more homogeneous material. The results of a corresponding comparison using all observations are not very different. For the sake of simplicity the evening observations are omitted. They would be represented by curves situated between those representing the noon and the night observations.

As expected, the relation between sky radiation and global radiation shows by far the largest variation with wavelength, particularly in the case of the noon observations. The proportion of ultraviolet at $320 \mathrm{~nm}$ to near infrared at 780 $\mathrm{nm}$ is thus about 14 times larger for sky radiation than for global radiation. For the night observations the corresponding proportion is about half as great. Obviously, these facts are closely connected with the wavelength-dependence of the scattering processes, which are most strongly in evidence about noon time, when sky radiation is relatively highest towards the ultraviolet part (see Fig. 7).

Also, the spectrum of a clear zenith sky is definitely higher for the shortest wavelengths than that of diffuse radiation from the whole celestial hemisphere (uppermost curves), which is in accordance with the visual impression of the colour distribution of a cloudless sky. This type of spectral shift towards zenith is somewhat more pronounced during the night than during the day.

In the case of an overcast sky (second pair of curves from above) there is again a slight predominance of the ultraviolet and blue content of the zenith radiation compared to the global radiation. There are also relatively high values towards the red end of the night zenith spectrum. As a whole, however, the spectral composition of radiation from a densely overcast sky is not very much different whether we consider the whole sky or the zenith sky only.

The lowermost curves show the ratio between the spectrum of global radiation from an overcast sky and that from a clear sky. As commented on previously (Section 8.1), the spectrum representing an overcast sky has a somewhat higher proportion of short-wave to long-wave radiation. 
Fig. 8. Variation with wavelength of the relation between different types of spectra. Relative units (see Fig. 6).

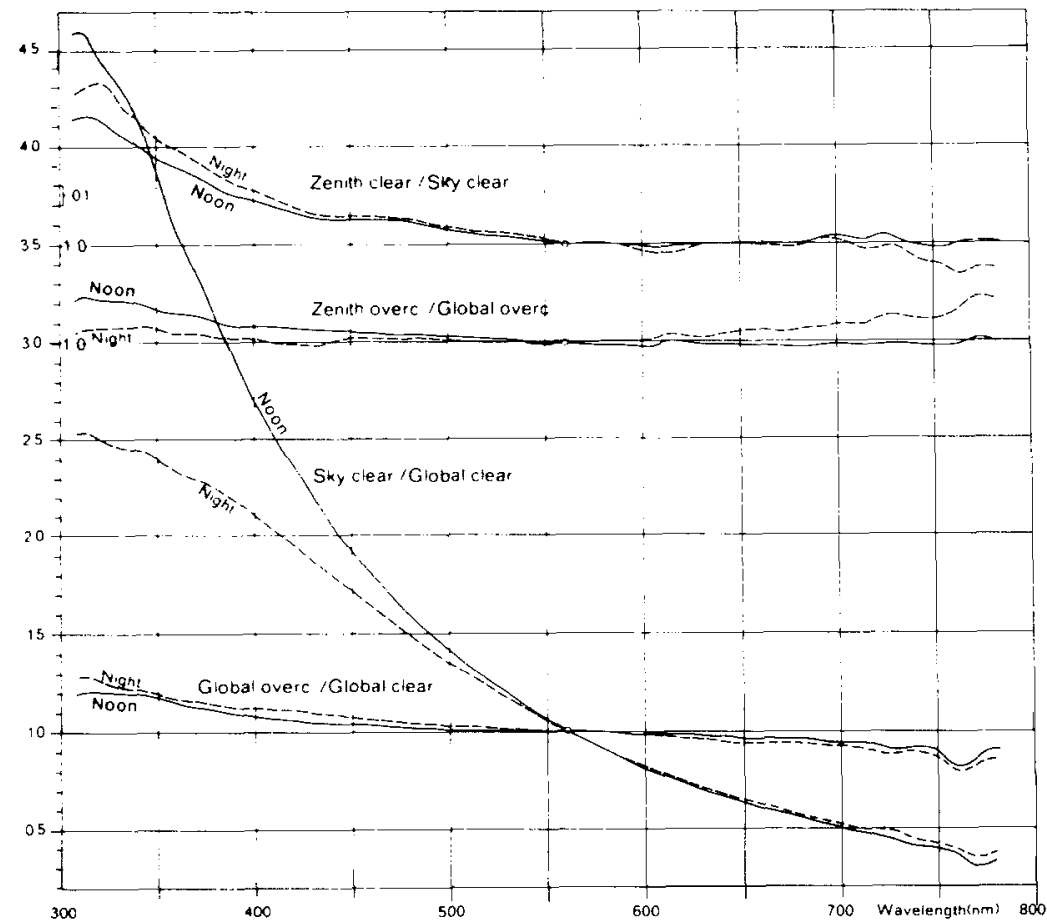

\subsection{Comparison with 'Rayleigh spectra'}

Spectral distributions of various components of solar radiation may be computed for a planeparallel Rayleigh atmosphere, using data worked out by Coulson et al. (1960) on the basis of Chandrasekar's theoretical work (1950).

In addition to all orders of molecular scattering, the computations may take into account the effect of a Lambert-type reflection from the earth's surface. The reflection is assumed to be independent of wavelength.

The surface of the Ny-Alesund area is of a very heterogeneous character, consisting partly of sea (with varying ice cover), partly of tundra (with varying snow cover) as well as extensive glaciers. It is hence difficult to establish a correct effective albedo. Coulson et al. (op. cit.) have tabulated spectral parameters for albedos equal to 0.25 and 0.80 , and both values are used here.

The computed spectra refer to solar altitudes of $30^{\circ}$ and $10^{\circ}$, which are close to the mean altitude of the sun during the noon and the night observations respectively.

The extraterrestrial solar spectrum may still not be considered definitively established. Our calculations are based on data published by Thekaekara (1974), as a result of a series of NASA experiments. Other recent data are very similar as far as the main features are concerned, but may show deviations in certain wavelength regions. Thus, the much used revised spectrum of Neckel and Labs (1981) is somewhat lower in the ultraviolet and somewhat higher between, say, 530 and $650 \mathrm{~nm}$.

The variation with wavelength of the ratios of the observed spectra to the theoretical ones is illustrated in Fig. 9. As before, both sets of spectra are normalized at $560 \mathrm{~nm}$, and all irradiances are adjusted so as to represent band-widths of $10 \mathrm{~nm}$. Comparisons with the 0.25 albedo distributions are entered as broken curves only in areas where they differ notably from those based on the 0.80 albedo distributions.

As attenuation of radiation in the case of the calculated spectra is due to molecular scattering only, atmospheric absorption is clearly in evidence, especially in the case of the night-curves. Thus, there is a very conspicuous effect of the Chappuis ozone bands. Although they are rather weak, they have a notable influence on practi- 
Fig. 9. Relation between observed and theoretical ('Rayleigh') spectra. Relative units (see Fig. 6).

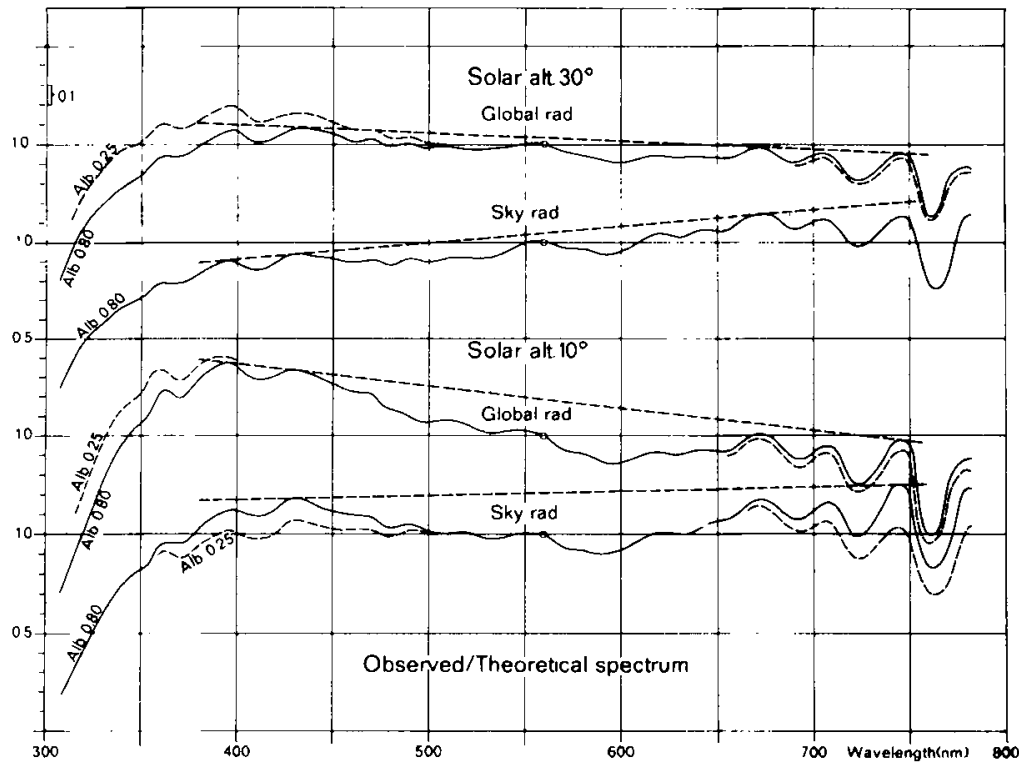

cally the whole visible part of the spectrum, with maximum absorption in the $560-620 \mathrm{~nm}$ region (Vigroux 1953). This fact should be remembered when comparing spectra normalized at $560 \mathrm{~nm}$. In cases with large atmospheric ozone content, such normalized spectra tend to be relatively high both in the blue and in the red part.

The broken straight lines in Fig. 9 are entered to visualize the increasing atmospheric absorption with decreasing solar altitude (more pronounced 'absorption dips'), and to indicate the general (non-linear) trend of the relation between observed and theoretical spectra. For global radiation, where direct solar radiation is a dominating component, the observed spectral irradiances increase relative to the theoretical ones as the wavelength decreases. This is in agreement with the fact that aerosol scattering is less dependent on wavelength than molecular scattering. Due to the same effect the corresponding relation for sky radiation has an opposite trend. The Rayleigh sky is more blue than the observed one.

\subsection{Comparison with the 'daylight spectra'}

For quite a long time investigations have been carried out to establish the spectral composition of daylight, and to some extent of the adjacent ultraviolet and infrared regions. Generally, only distributions in relative units are discussed, either of light coming from special parts of the sky, or of light reflected from a white plate facing the celestial hemisphere in various ways. For the sake of simplicity we refer to these distributions as 'daylight spectra'.

The observation conditions, including solar altitude, are usually not very well specified in these daylight studies, and it may therefore be difficult to draw conclusions when comparing the results. It has turned out, however, that when grouped according to chromaticity coordinates or correlated colour temperature (defined and discussed in later sections) the spectra within each group have approximately the same course, even if the observation conditions and measuring techniques differ considerably. This fact may justify the calculation of average or combined spectra representing different phases of daylight.

Using the so-called characteristic vector method, Judd et al. (1964) on the basis of 622 spectral distributions calculated typical daylight spectra for a selection of correlated colour temperatures. In Fig. 10 the noon global spectrum for $\mathrm{Ny}$-Allesund, clear sky, is compared with the typical, combined spectra for correlated colour temperature values of $6500^{\circ} \mathrm{K}$ (open rings) and $7500^{\circ} \mathrm{K}$ (dots). These two distributions, often referred to as $D_{65}$ and $D_{75}$, belong to the standard 


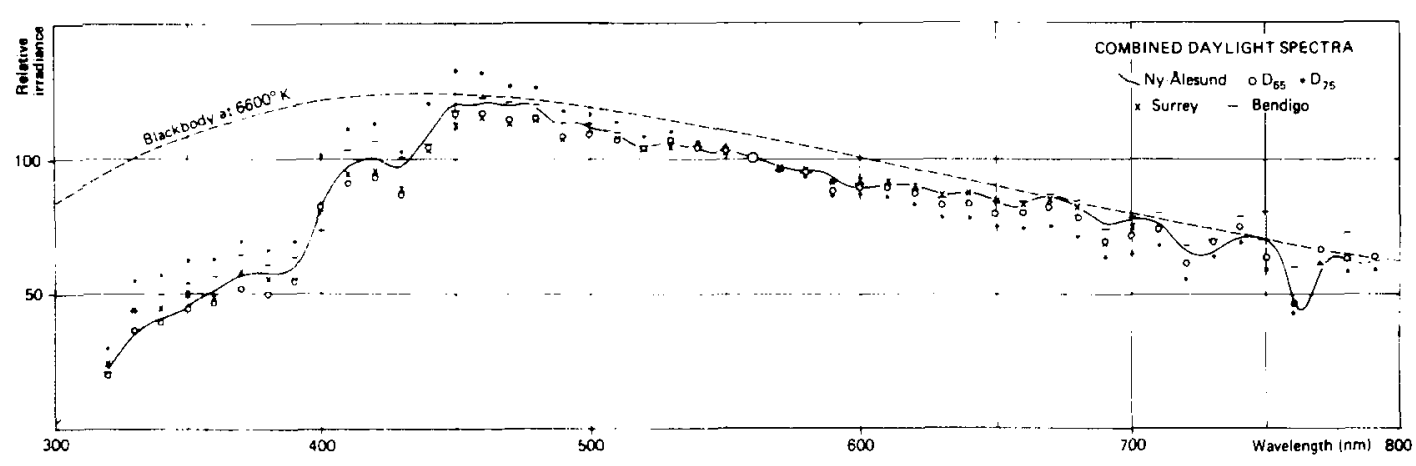

Fig. 10. A selection of observed and reconstituted 'daylight spectra'. Relative units (see Fig. 6).

daylight spectra recommended by CIE (Commission Internationale de l'Eclairage). Especially $D_{6 s}$ has been widely used as a reference spectrum representative of average daylight.

It appears from Fig. 10 that the general course of $D_{b s}$ does not differ much from that of the $\mathrm{Ny}$-Alesund curve. $\mathrm{D}_{0}$ s is somewhat lower both in the violet-blue part and in the red part. The light represented by $\mathrm{D}_{-5}$, on the other hand, is much more blue, i.e. it has a considerably higher correlated colour temperature than the light represented by the $\mathrm{Ny}$-Alesund spectrum.

It has later been pointed out that the relative content of ultraviolet radiation in several cases may be notably larger than that of Judd et al.'s $D$-spectra. As an example the average spectra for a correlated colour temperature close to $6500^{\circ} \mathrm{K}$ found by Tarrant \& Brock (1975) and Dixon (1978) are indicated in Fig. 10. The former authors made their observations in Surrey, England, the latter one at Bendigo, about $130 \mathrm{~km}$ NNW of Melbourne, Australia. The Bendigo spectrum had to be slightly smoothed in order to apply to a band-width of about $10 \mathrm{~nm}$. It appears that both distributions are higher in the ultraviolet than that of $D_{b s}$ and, to a large extent, that of Ny-Allesund. The Surrey spectrum is lower than $\mathrm{Ny}$-Ảlesund in the shortwave part of the visible region, while the Bendigo spectrum is mostly higher. For the rest of the visible region both the Surrey (which ends at $700 \mathrm{~nm}$ ) and Bendigo spectra are almost identical with that of
Ny-Ålesund. The somewhat more pronounced minima at $690-700 \mathrm{~nm}$ and $720-730 \mathrm{~nm}$ in the spectra from intermediate latitudes are presumably due to the usually larger water vapour content of the atmosphere over these areas. (The mean solar altitudes are not known.)

We may conclude that the form of the $\mathrm{Ny}$. Alesund spectrum for noon global radiation, clear sky, agrees quite well with spectra from intermediate latitudes referring to a correlated colour temperature of about $6500^{\circ} \mathrm{K}$. To a large extent this also applies to the Ny-Ålesund global spectra for an overcast sky (more blue, less red, i.e. somewhat closer to $\mathrm{D}_{75}$ ), and the $\mathrm{Ny}$-Ålesund spectra for lower solar altitudes (which i.a. have the larger water vapour dips mentioned above).

The broken curve in Fig. 10 represents a black body at a temperature of $6600^{\circ} \mathrm{K}$. This distribution is not normalized at $560 \mathrm{~nm}$. By a suitable adjustment of the relative spectral irradiances the black body curve very nearly passes through the 'wave crests' of the Ny-Ålesund curve for wavelengths above $450 \mathrm{~nm}$. Disregarding atmospheric absorption the two curves thus have practically the same course in this wavelength region. Towards lower wavelengths the observed irradiances become rapidly much smaller, not least because of the occurence of several strong Fraunhofer lines and the increasing ozone absorption. Some further comments on this special comparison are given in a following discussion on chromaticities and correlated colour temperatures. 


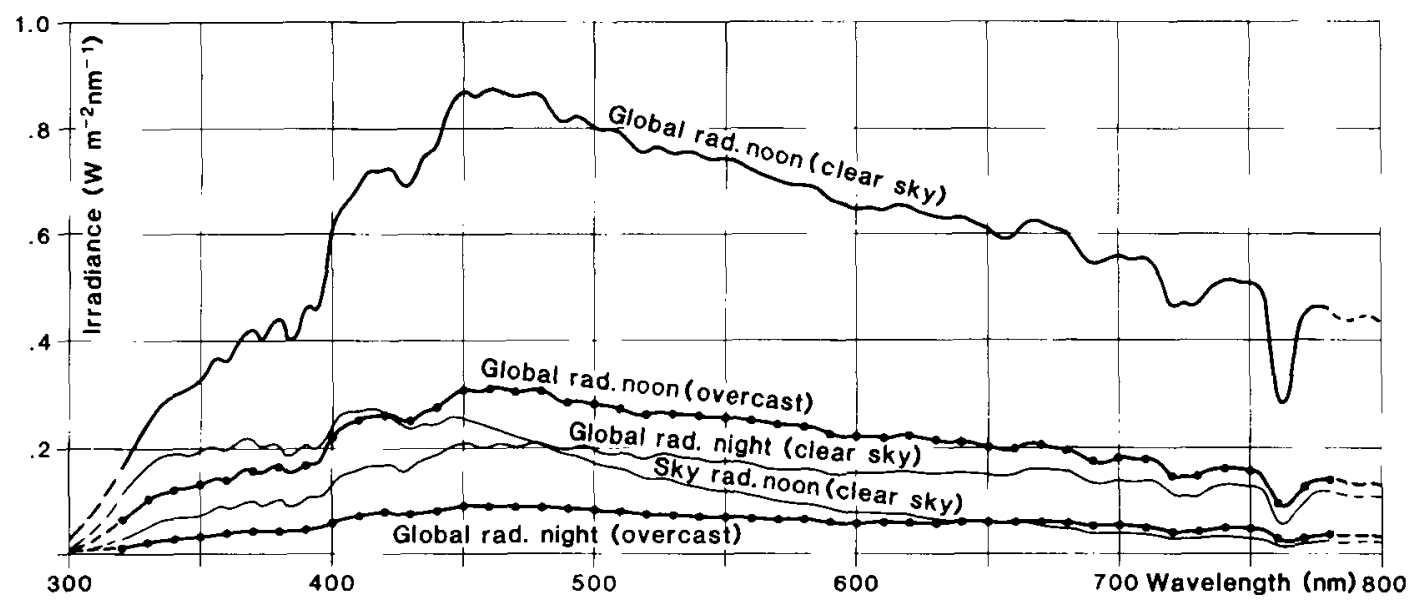

Fig. 11. A selection of $\mathrm{Ny}$-Ålesund spectra in absolute units.

\subsection{Absolute spectral irradiances}

Up to now we have considered relative spectral distributions. As mentioned before, one has to be careful when interpreting differences between these distributions, not least because of the varying and usually unknown ozone absorption at the reference wavelength, which may raise (high ozone content) or lower the relative spectral irradiances on both sides.

Fig. 11 shows a selection of $\mathrm{Ny}$-Ålesund spectra in absolute units, estimated in accordance with the method outlined in Section 7. The halfband width is the one used when the measurements were made $(3.3 \mathrm{~nm})$. Number of observations and mean air masses are found in Table 2 . The spectra refer to a mean sun-earth distance during the observation period, 20 June to $2 \mathrm{Au}$ gust. (An adjustment to the annual mean sunearth distance would mean an increase of the irradiances of about $3 \%$.) The diagram demonstrates the superiority of the global radiation energy received at noon on a clear day. From 300 $\mathrm{nm}$ the spectral irradiances increase to a value between 0.40 and $0.45 \mathrm{~W} \mathrm{~m}^{-2} \mathrm{~nm}^{-1}$ in the near ultraviolet, proceed to a maximum of about twice this value in the region 450 to $480 \mathrm{~nm}$, and then decrease again more slowly to about $0.45 \mathrm{~W} \mathrm{~m}^{-2}$ $\mathrm{nm}^{-1}$ at the infrared end.

To facilitate comparison with other data the irradiances in Table 3 are adjusted so as to refer to a half-band width of $10 \mathrm{~nm}$, and, by means of the regression equations in Section 7, to air mas- ses corresponding to true solar altitudes of $30^{\circ}$ and $10^{\circ}$ respectively. Some percentage relations between these distributions are shown in Fig. 12. The global irradiances for an overcast day are about $40 \%$ of those for a clear day at the shortwave end of the spectrum, decreasing to slightly above $30 \%$ at the long-wave end. Apart from a marked drop in the ultraviolet (ozone absorption), the corresponding relations between global irradiances for night and day for a clear sky keep fairly close to $25 \%$. We may further note that while the sky radiation on a clear day is responsible for more than half of the ultraviolet content of the global radiation, it does not give more than about $5 \%$ of the near infrared radiation.

The irradiances of the Ny-Alesund distribution in Fig. 13 are slightly increased in proportion to the corresponding ones in Table 3 in order to be representative of the annual mean sun-earth distance, and thus be comparable with the spectra of a Rayleigh atmosphere shown in the same diagram. As pointed out before, the Ny-Allesund distribution is comparatively high in the violetblue region, where it is somewhat higher than the Rayleigh spectrum for a ground albedo of 0.25 .

As in the case of relative 'daylight spectra', it was difficult to find spectral distributions in absolute units from other locations that could serve as a relevant basis of comparison. Often the observation conditions are insufficiently known, or the distributions refer either to quite different solar altitudes or to very wide spectral bands. 
Table 3. Average spectral distributions of global radiation $\left(\mathrm{Wm}^{-2} \mathrm{~nm}^{-1} \cdot 10^{3}\right)$ for solar altitudes of $30^{\circ}$ and $10^{\circ}$, and a half-band width of $10 \mathrm{~nm}$.

\begin{tabular}{|c|c|c|c|c|c|c|c|c|c|}
\hline \multirow{2}{*}{$\begin{array}{c}i \\
\text { nm }\end{array}$} & \multicolumn{2}{|c|}{ Clear sky } & \multicolumn{2}{|c|}{ Overcast } & \multirow{2}{*}{$\begin{array}{c}\lambda \\
\mathrm{nm}\end{array}$} & \multicolumn{2}{|c|}{ Clearsky } & \multicolumn{2}{|c|}{ Overcast } \\
\hline & $30^{\circ}$ & $10^{\circ}$ & $30^{\circ}$ & $10^{\circ}$ & & $30^{\circ}$ & $10^{\circ}$ & $30^{\circ}$ & $10^{\circ}$ \\
\hline 320 & 157 & 28 & 64 & 14 & 550 & 707 & 172 & 243 & 71 \\
\hline 30 & 244 & $\$ 2$ & 104 & 27 & 60 & 690 & 166 & 236 & 68 \\
\hline 40 & 286 & 66 & 118 & 32 & 70 & 673 & 156 & 231 & 65 \\
\hline 50 & 317 & 75 & 125 & 35 & 80 & 662 & 156 & 224 & 63 \\
\hline 60 & 350 & 83 & 133 & 39 & 90 & 638 & 148 & 214 & 60 \\
\hline 70 & 395 & 92 & 151 & 44 & & & & & \\
\hline 80 & 400 & 95 & 157 & 46 & 600 & 621 & 146 & 208 & 58 \\
\hline \multirow[t]{2}{*}{90} & 422 & 100 & 162 & 47 & 10 & 623 & 150 & 209 & 59 \\
\hline & & & & & 20 & 622 & 150 & 208 & 60 \\
\hline 400 & 571 & 135 & 212 & 62 & 30 & 602 & 146 & 201 & 58 \\
\hline 10 & 672 & 160 & 241 & 72 & 40 & 600 & 149 & 199 & 58 \\
\hline 20 & 695 & 165 & 248 & 75 & 50 & 580 & 146 & 192 & 57 \\
\hline 30 & 679 & 165 & 238 & 72 & 60 & 575 & 148 & 188 & 56 \\
\hline 40 & 756 & 183 & 260 & 79 & 70 & 591 & 155 & 194 & 59 \\
\hline 50 & 830 & 201 & 291 & 88 & 80 & 566 & 149 & 189 & 58 \\
\hline 60 & 834 & 206 & 293 & 89 & 90 & 525 & 132 & 168 & 50 \\
\hline 70 & 827 & 204 & 287 & 87 & & & & & \\
\hline 80 & 822 & 203 & 288 & 88 & 700 & 537 & 134 & 172 & 52 \\
\hline \multirow[t]{2}{*}{90} & 785 & 192 & 267 & 82 & 10 & 522 & 136 & 170 & 52 \\
\hline & & & & & 20 & 453 & 108 & 139 & 40 \\
\hline 500 & 770 & 188 & 264 & 80 & 30 & 453 & 110 & 139 & 41 \\
\hline 10 & 754 & 186 & 260 & 79 & 40 & 487 & 129 & 155 & 47 \\
\hline 20 & 721 & 181 & 248 & 75 & 50 & 484 & 128 & 151 & 46 \\
\hline 30 & 723 & 176 & 249 & 74 & 60 & 321 & 66 & 85 & 22 \\
\hline \multirow[t]{2}{*}{40} & 717 & 175 & 245 & 72 & 70 & 400 & 96 & 123 & 32 \\
\hline & & & & & 80 & 429 & 112 & 132 & 37 \\
\hline
\end{tabular}

Fig. I2. Percentage relation between different types of spectra in absolute units.

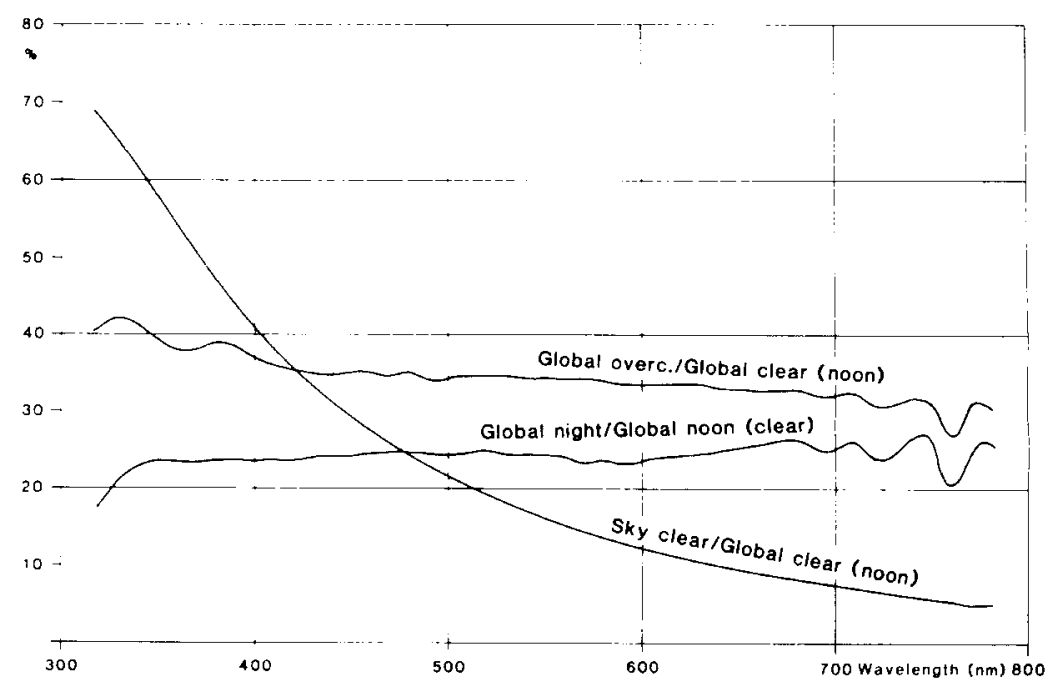


Kok (1972) on the basis of measurements from Pretoria has published spectral irradiances for air mass 2 . The values are somewhat uncertain, as they to a large extent are obtained by extrapolation. The observations were made during a period of one year, and the average sun-earth distance is presumably not far from the annual mean.

The Pretoria distribution for global radiation (clear sky) is shown in Fig. 13. As the measurements were made with a quartz prism monochromator (increasing solution with decreasing wavelength) the course of the short-wave part of the spectrum was somewhat smoothed to make it more comparable with the other spectra.

For wavelengths above $580 \mathrm{~nm}$ the Pretoria spectrum is very close to that of $\mathrm{Ny}$-Ålesund. For shorter wavelengths in the visible part the former spectrum is considerably lower. This may be due partly to a higher spectral albedo for these wavelengths in Ny-Ålesund, and probably more important, to the fact that the Pretoria measurements were made in a rural area, where the scattering by aerosols is larger. In the ultraviolet the two distributions approach again. Two circumstances may here be of importance. Both according to the mean geographical ozone distribution (Bower \& Ward 1982), and the height of the station above sea level $(1400 \mathrm{~m})$, the ultraviolet intensity should be relatively strong in Pretoria, in spite of a larger aerosol scattering.

McCartney (1978) measured spectral distributions of the visible part of global radiation at a station somewhat south of Nottingham, in the central part of England. The spectral irradiances for a solar altitude of $30^{\circ}$, indicated in Fig. 13, should probably be raised by about $3 \%$ to refer to the annual mean sun-earth distance. However, in any case this distribution, which represents 'average turbidity conditions' in the area, is evidently far more influenced by aerosol scattering than that of Pretoria.

It would be of considerable interest to compare the observed spectra with corresponding ones based on the extraterrestrial solar spectrum, modified theoretically by the various attenuation processes taking place in the atmosphere, as well as the effect of reflection from the earth's surface. In the present discussion only a first approximation is made, by computing a sort of 'border spectrum', which would occur if molecular scattering and a non-wavelength dependent ground reflection were the only modifying processes present.

In addition to molecular scattering a realistic model has to allow for selective absorption by atmospheric gases and the spectral attenuation effect of aerosols. Furthermore, the influence of

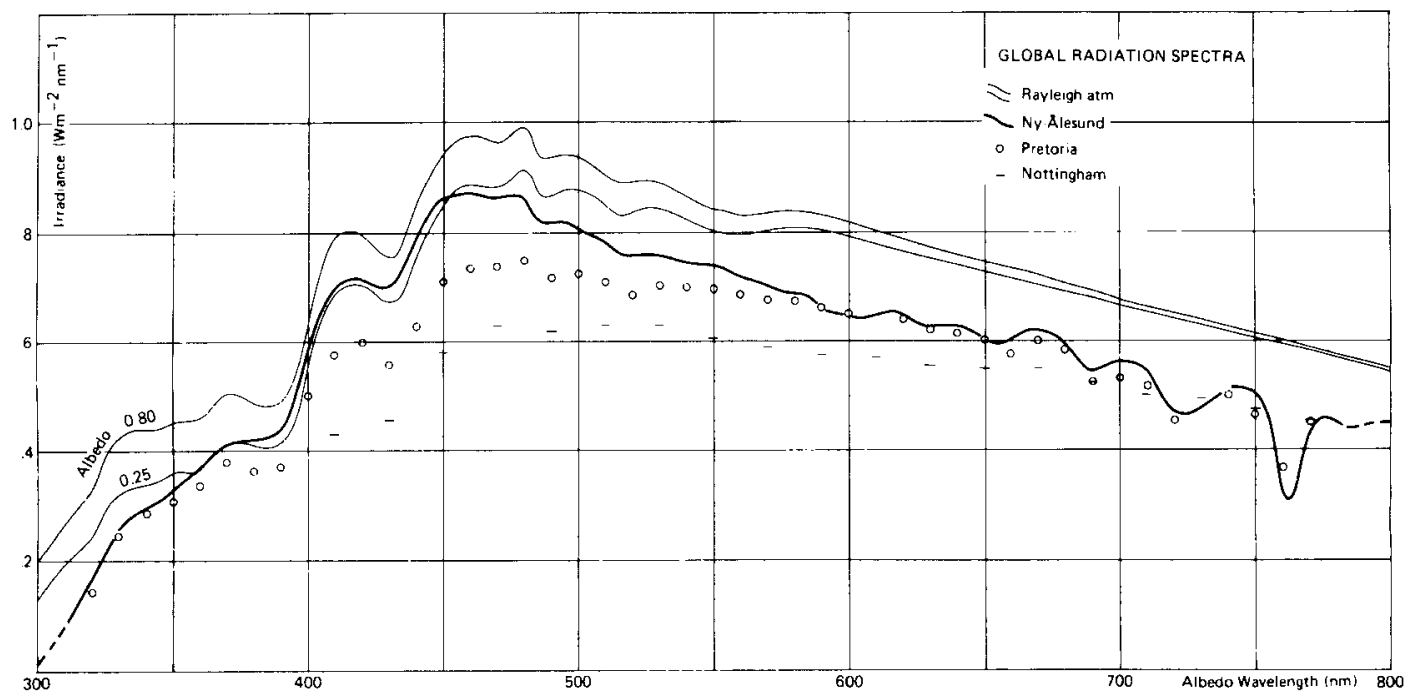

Fig. 13. Comparison of observed and theoretical spectra in absolute units. 
multiple reflection between the earth's surface and the atmosphere, including the spectral albedo of the ground, has to be taken into account.

Simplified models of these complex processes have been worked out, such as those proposed by Dave et al. (1975), Leckner (1978), and by Brine and Iqbal (1983). These models seem to give reasonable results. However, sufficiently reliable comparisons with observed spectra are still lacking. Even the scanty amount of relevant observations available is difficult to use as a basis of comparison, while the model input parameters (ozone content, aerosol characteristics, etc.) are imperfectly known. Strictly, as mentioned before, even the basic input parameter, the extraterrestrial solar spectrum, is not definitely established.

It may be mentioned that there have for some time now been carried out sun photometer measurements in $\mathrm{Ny}$-Alesund of direct solar irradiance within several wave-bands from 400 to 1910 $\mathrm{nm}$. This material should give good information about the average as well as extreme values of aerosol characteristics, and the total water vapour content of the air. Together with results of observations made of the albedo of the ground and the amount of ozone, this information should provide a good basis for calculations of various types of average and extreme spectra.

\section{Characteristic deductions}

\subsection{Light}

Most radiation-dependent processes are spectrally selective. A well known example is photosynthesis, which is closely connected with the absorption spectra of different types of chlorophylles. Equally well known in this respect is the concept of light, i.e. radiation evaluated in proportion to its capability of stimulating the sense of sight, which is also highly dependent on wavelength.

The author has made a series of illuminance measurements in Ny-Ålesund. It may be of interest to compare some results of these measurements with corresponding illuminances computed on the basis of spectral irradiances and the spectral sensitivity of the human eye.
If $I_{\lambda}$ is the spectral irradiance $\left(\mathrm{Wm}^{-2} \mathrm{~nm}^{-1}\right)$, the total illuminance $E$ (lux) is given by

$$
\mathrm{E}=\mathbf{K} \int_{\lambda_{1}}^{\lambda_{2}} \mathrm{~V}_{\lambda_{2}} \mathbf{I}_{\lambda} \mathrm{d} \lambda
$$

where $\lambda_{1}$ and $\lambda_{2}$ are wavelengths indicating the limits of the spectral region stimulating the sense of sight, $\mathrm{K}$ is the maximum luminous efficiency, equal to 683 lumen $W^{-1}$ (CGPM adopted value, 1979), and $V_{\lambda}$ is the relative luminous efficiency of the 'normal light adapted human eye' (CIE adopted standard observer, 1931).

The expression above is evaluated using the average global radiation spectra (clear sky) discussed earlier. The illuminances obtained for noon, evening, and night are entered as ringed crosses in Fig. 14. The dots represent illuminance measurements carried out in Ny-Ålesund during May-June 1979 and 1980. Only situations with a completely clear sky, or with insignificant clouds close to the horizon, are considered. Shorter or longer periods with favourable observation conditions occurred on 24 days in all, and the total number of observations was 189 . The Hagner photometer used was checked against a standard lamp (calibrated at the National Physical Laboratory, London) as well as against secondary standard instruments.

It clearly appears from the diagram that within the range considered the illuminance is to a good approximation a linear function of the solar altitude, a connection that has been pointed out by several authors (cf. Schieldrup Paulsen 1968). It needs scarcely be added that the linearity does not apply for very low solar altitudes, as indicated by the broken curve in the diagram. The three calculated illuminance values deviate $0.3 \%$ (noon), 1.0\% (evening), and 2.9\% (night) from the values found for the same solar altitudes on the linear regression line based on the photometer observations. Taking into account the variability to be expected because of varying atmospheric conditions and inaccuracies of the measuring device, the agreement between the two sets of values seems very satisfactory.

\subsection{Colour co-ordinates}

The colour of light may be defined quantitatively 
by the CIE chromaticity co-ordinates $(x, y)$, which are obtained from the so-called tristimulus values:

$$
\begin{aligned}
& \lambda_{2} \\
& X=k \int \bar{x}_{\lambda} I_{\lambda} d \lambda \\
& \lambda_{1} \\
& \lambda_{2} \\
& \mathrm{Y}=\mathrm{k} \int_{\lambda_{1}} \overline{\mathrm{y}} \lambda_{\lambda} \mathrm{d} \lambda \\
& \lambda_{2} \\
& \mathrm{Z}=\mathrm{k} \int_{\lambda_{1}} \overline{\mathrm{z}} \mathrm{I}_{\lambda} \mathrm{d} \lambda
\end{aligned}
$$

where $\overline{\mathbf{x}}_{\lambda}, \bar{y}_{\lambda}$ and $\bar{z}_{\lambda}$ are colour matching functions (cf. e.g. Wyszecki \& Stiles 1982). The chromaticities are then specified by

$$
x=\frac{X}{X+Y+Z} \text { and } y=\frac{Y}{X+Y+Z}
$$

Table 4 shows chromaticity co-ordinates for some main average spectra from $\mathrm{Ny}$-Ålesund. As these colour parameters are determined by the form of the spectral distribution only, smaller deviations of the mean solar altitude from the reference altitudes $30^{\circ}$ and $10^{\circ}$ are of no importance.

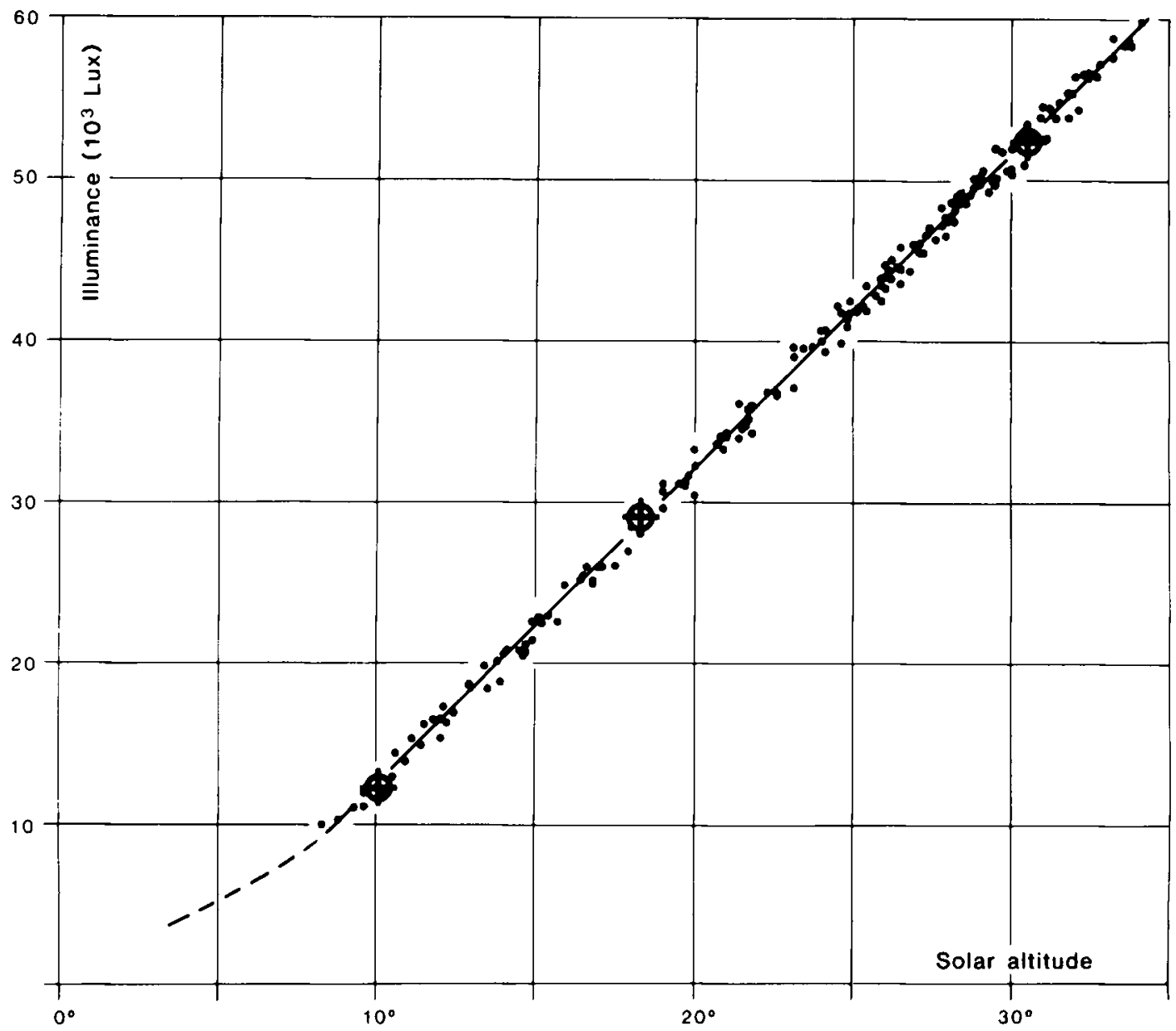

Fig. 14. Observed (dots) and calculated (ringed crosses) daylight illuminances versus solar altitude for situations with a clear sky. 
Table 4. Parameters characterizing the chromaticity of different types of daylight falling on a horizontal plane in Ny-Alesund.

\begin{tabular}{lccccc}
\hline & $\begin{array}{c}\text { Solar } \\
\text { alt. }\end{array}$ & \multicolumn{2}{c}{$\begin{array}{c}\text { Chromaticity } \\
\text { co-ordinates }\end{array}$} & $\begin{array}{c}\text { Correl. } \\
\text { col.temp. } \\
{ }^{\circ} \mathrm{K}\end{array}$ & $\begin{array}{c}\text { Point } \\
\text { no. in } \\
\text { Fig. 15 }\end{array}$ \\
\hline Sun and clear sky & $30^{\circ}$ & .3116 & .3230 & 6,620 & 1 \\
& $10^{\circ}$ & .3097 & .3222 & 6,750 & 2 \\
Overcast sky & $30^{\circ}$ & .3080 & .3207 & 6,850 & 3 \\
& $10^{\circ}$ & .3021 & .3161 & 7,310 & 4 \\
Clear sky alone & $30^{\circ}$ & .2441 & .2504 & 35,150 & 5 \\
& $10^{\circ}$ & .2492 & .2627 & 20,900 & 6 \\
Clear zenith sky & $30^{\circ}$ & .2344 & .2350 & & \\
& $10^{\prime \prime}$ & .2389 & .2482 & 50,000 & 8 \\
\hline
\end{tabular}

A survey of the co-ordinates is obtained by plotting them in a CIE chromaticity diagram, Fig. 15. Here are also entered the chromaticities of the Pretoria and Nottingham spectra discussed previously. (The co-ordinates for Nottingham are calculated on the basis of a spectral diagram in the work of McCartney (1978).) The solid curve indicates the chromaticities of a black body as a function of absolute temperature, and the broken curve is the CIE daylight D-locus, given by the expression (Judd et al. 1964):

$y_{D}=-3.000 x_{D}^{2}+2.870 x_{D}-0.275$

In accordance with most previous investigations, all points in the diagram are slightly above, i.e. on the green side of the black body curve. However, the $\mathrm{Ny}$-Allesund points representing different phases of global radiation as well as that of Pretoria are closer to this curve than is the CIE daylight locus.

Judging by the colour matching tests leading to the so-called MacAdam ellipses (MacAdam 1942), assumed to give a measure of least noticeable colour difference, the differences between the $\mathrm{Ny}$-Ålesund types of daylight represented by Points 1 to 3 are scarcely perceptible.

However, the distances from this group to the co-ordinates of daylight observed in Pretoria and Nottingham (Points 9 and 10) are so large (more than 10 MacAdam ellipse radii) that there should be a clear colour difference.
As would be expected, diffusely scattered sky and zenith radiation give a more bluish light, and the chromaticities are situated near the hightemperature region of the black body curve. They are, however, farther from this curve than the chromaticities of total daylight from sun and sky. This tendency of increasing 'green shift' towards the high temperature end of the black body curve has been observed in chromaticity diagrams for other locations as well (cf. Henderson 1977).

\subsection{Colour temperature}

The spectral distribution of different phases of solar radiation may, in some wavelength regions, deviate considerably from the corresponding 'closest' black body distribution (see Fig. 10). However, as shown in the preceding section, the chromaticities of daylight are generally very close to the black body locus. It may therefore be useful to identify the observed radiation sources, both regarding colour and general course of the spectral distribution, in terms of the so-called correlated colour temperature, which is the temperature of a black body giving the nearest chromaticity match to the source considered.

The correlated colour temperature may be estimated by means of the isoterms in MacAdam's chromaticity diagram (Kelly 1963). Temperatures for Ny-Ålesund are given in the last column of Table 4. Evidently, this way of characterizing spectral distributions is less useful for zenith 


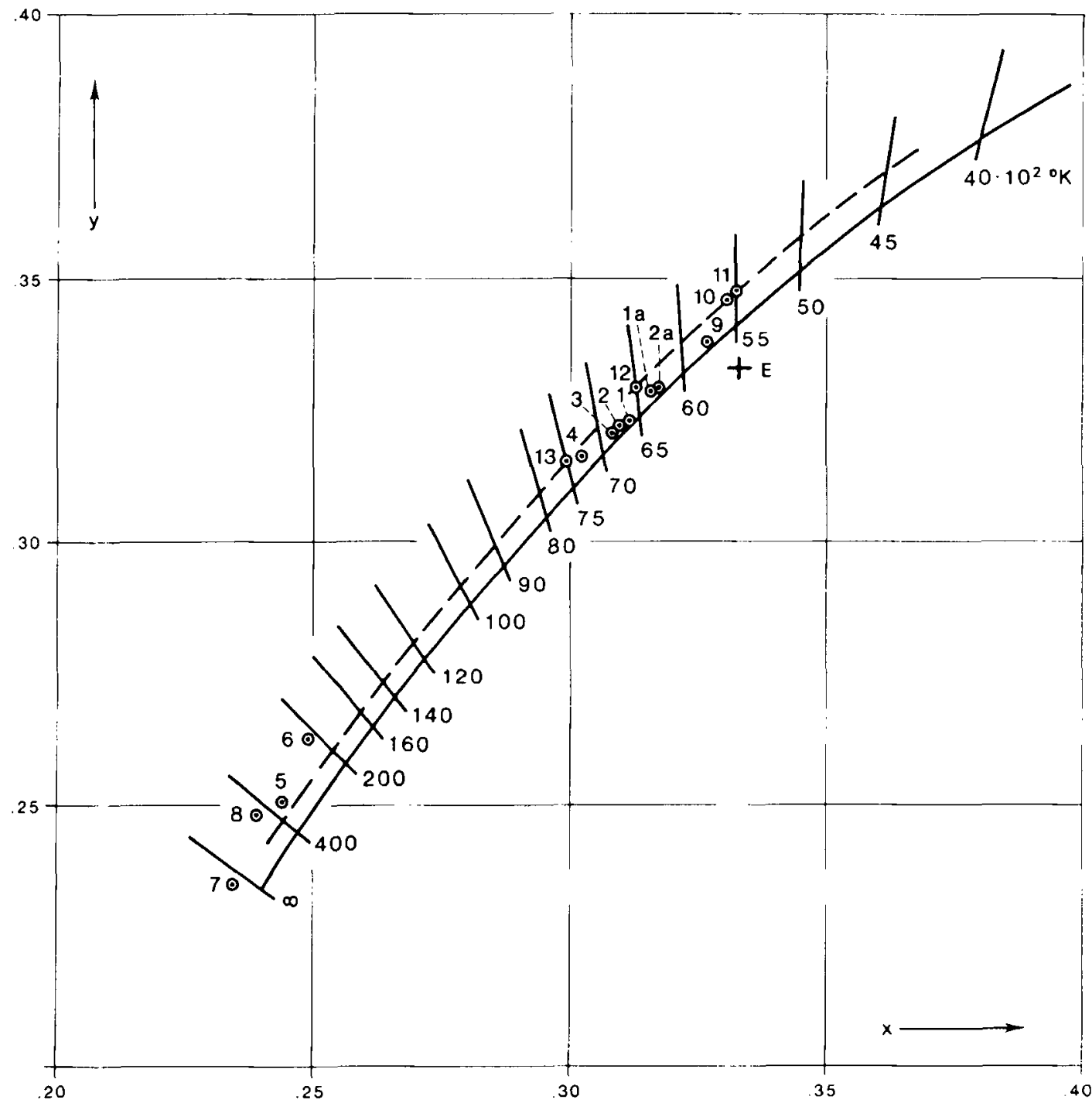

Fig. 15. Chromaticity diagram showing the black-body locus (solid curve) and the CIE daylight D-locus (broken curve). Points 1 to 8, representing different phases of daylight in $\mathrm{Ny}$-Alesund, are specified in the last column of Table 4. Points 9 and 10 indicate the chromaticities (clear sky plus sun) at Pretoria and Nottingham respectively. Points $11,12,13$ represent the standard daylight sources $D_{55}, D_{65}$, and $D_{75}$. Point $2 a$ shows the estimated chromaticity for a clear night with the same ozone absorption as that occurring during the middle of the day, while Point la indicates the colour of noon daylight under a clear sky, provided there were no ozone absorption at all. Point $\mathrm{E}$ (cross) is the white point corresponding to constant spectral irradiance.

radiation from a clear sky. In this case the concept of correlated colour temperature collapses, and it is not possible to match the chromaticities with those of a black body.

Fig. 15 shows that the lowest colour temperature ('least blue' daylight) is that of Nottingham $\left(5590^{\circ} \mathrm{K}\right)$, followed by Pretoria $\left(5770^{\circ} \mathrm{K}\right)$. For $\mathrm{Ny}$-Ålesund the corresponding value for a clear sky is $6620^{\circ} \mathrm{K}$, the individual days of observation ranging from $6300^{\circ}$ to $6800^{\circ} \mathrm{K}$. For an overcast sky $\left(6850^{\circ} \mathrm{K}\right)$, the range of the individual days is somewhat larger, $6600^{\circ}$ to $7300^{\circ} \mathrm{K}$, no doubt due 
to the varying optical thickness of the cloud cover.

It is a bit unexpected that the light at midnight has a higher colour temperature than the noon light. This is especially clearly in evidence for an overcast sky. In the case of diffusely scattered radiation from the whole celestial hemisphere, or from the zenith sky, the relation is opposite: the scattered radiation during night has the lowest colour temperature and thus the faintest blue hue.

These differences between the character of noon and night light have probably two main causes. In the case of global radiation the explanation may to some extent be the fact that the 'blue' scattered radiation represents a greater part of the total amount during the night than during the day. Still more significant in this connection, however, seems to be the influence of strong ozone absorption of radiation from a low sun in the wide wavelength region covered by the Chappuis bands. centred at about $600 \mathrm{~nm}$. The magnitude of this effect may be estimated by 'straightening out' the concave course in this wavelength interval of the relation between the night and noon spectrum (Fig. 7). In Fig. 15 is shown the estimated change of the chromaticity co-ordinates for a clear night (Point 2) when the ozone absorption is supposed to be the same as the one taking place during the middle of the day. The chromaticity is then shifted to Point $2 a$, which is clearly on the yellow side of the noon daylight (Point 1).

Point la indicates the position of the noondaylight chromaticity provided the atmosphere did not contain any ozone at all. It seems quite obvious that ozone absorption may have a considerable influence on the colour of daylight. Varying absorption, due to changes of the solar altitude or the ozone content of the atmosphere, may cause noticeable shifts of the chromaticity coordinates.

As to the diffusely scattered radiation (Points 5 to 8 ) the dominating effect seems to be selective scattering processes, which makes the scattered light reaching the earth's surface poorer in the blue part when the sun is low.

Some comments on the relation between spectral irradiances observed at different solar altitudes may be found in Section 8.2. In this con- nection it should be remembered that there is a fundamental difference between the course of the spectral distribution of irradiances and the corresponding distribution of illuminances responsible for the sensation of colour.

Acknowledgements. - I am particularly indebted to Bjarne Hisdal for helpful discussions and suggestions during this research. My thanks are also due to Arvid Skartveit and Kjell Henriksen, who read the manuscript and contributed valuable criticism, and to Ivar Kristensen for help with the data processing. The work was supported by a grant from Norsk Hydros Fond.

\section{References}

Bower, F.A. \& Ward, R.B. 1982: Stratospheric ozone and man. Vol. I. CRC Press, Boca Raton, Florida. $217 \mathrm{pp}$.

Brine, D.T. \& Iqbal, M. 1983: Diffuse and global solar spectral irradiance under cloudless skies. Solar Energ! 30(5), 447-453.

Budd, W. 1964: Integrating sphere for the photometry of the sky. Appl. Optics 3(8).939-941.

Chandrasekhar, S. 1960: Radiative transfer. (2nd ed.) Dover Publ., New York. 393 pp.

Coulson, K.L., Dave, J.V. \& Sekera, Z. 1960: Tables related to radiation emerging from a planetary atmosphere with Rayleigh scattering. Univ. Calif. Press, Berkeley. 548 pp.

Dave, J.V., Halpern, P. \& Braslau, N. 1975: Spectral distribution of the direct and diffuse solar energy received at sea-level of a model atmosphere. Rep. No. G320-3332, IBM Palo Alto Scient. Center.

Dixon, E.R. 1978: Spectral distribution of Australian daylight. J. Opt. Soc. Am. 68(4).437-450.

Grum, F. \& Luckey, G.W. 1968: Optical sphere paint and a working standard of reflectance. Appl. Optics 7(11). $2289-2294$.

Henderson, S.T. 1977: Daylight and its spectrum. (2nd ed.) Adam Hilger Lid., Bristol. 349 pp.

Hisdal, V. 1969: A comparative study of the spectral composition of the Zenith sky radiation. Norsk Polarinst. Arbok 1967,7-27.

Hisdal, V. 1980: On the zero-point deviation of Eppley pyranometers. Norsk Polarinst. Skrifter 172,5-9.

Hunt, R.W.G. 1975: The reproduction of colour. (3rd ed.) Fountain Press, London. 614 pp.

Judd, D.B., MacAdam, D.L. \& Wyszecki, G. 1964: Spectral distribution of typical daylight as a function of correlated color temperature. J. Opt. Soc. Am. $54(8), 1031-1040$.

Kaase, H. 1973: Depolarisation der an $\mathrm{BaSO}_{4}$ diffus reflektierten Strahlung. Optik 38(4), 433-436.

Kelly, K.L. 1963: Lines of constant correlated color temperature based on MacAdam's (u,v) uniform chromaticity transformation of the CIE diagram. $J$. Opt. Soc. Am. 53(8),999-1002. 
Kok, C.J. 1972: Spectral irradiance of daylight at Pretoria. J. Phys. D.: Appl. Phys. 5, 1513-1520 and L 85-88.

Leckner, B. 1978: The spectral distribution of solar radiaton at the earth's surface - elements of a model. Solar Energy 2O(2), 143-150.

MacAdam, D.L. 1942: Visual sensitivities to color differences in daylight. J. Opt. Soc. Am. 32(5), $247-274$.

McCartney, H.A. 1978: Spectral distribution of solar radiation. II: global and diffuse. Quart. J. R. Met. Soc. 104(442), 911-926.

Middelton, W.E.K. \& Sanders, C.L. 1953: An improved sphere paint. Illum. Eng. 48(5), 254-256.

Neckel, H. \& Labs, D. 1981: Improved data of solar spectral irradiance from 0.33 to $1.25 \mu$. Solar Phys. $74,231-249$.

Richter, M. \& Terstiege, H. 1970: Bariumsulfat-Tabletten als Standard für Farbmessungen von Aufsichtfarben. Lichttechnik 22(9), 446-449.

Schieldrup Paulsen, H. 1968: A study of the radiation climate of southern Norway. Part II. Arbok Univ.
Bergen, Mat.-Nat.Serie (2). 74 pp.

Schneider, W.E., Waters, W.R. \& Jackson, J.K. 1968 : Development of a high-intensity standard of total and spectral irradiance. NBS Rept. 9899, U.S. Dept. Commerce. 81 pp.

Tarrant, A.W.S. \& Brock, J.R. 1975: Further studies of the spectral power distribution of daylight in the ultraviolet region. Compte Rendu CIE, London 1975 , 384-392.

Thekaekara, M.P. 1974: Extraterrestrial solar spectrum, $3000-6100 \AA$ at $1-\AA$ intervals. Appl. Optics 13(3), 518-522.

Vigroux, E. 1953: Contribution à l'étude expérimentale de l'absorption de l'ozone. Ann. Phys. 8,709-762.

Walsh, J.W.T. 1961: The science of daylight. Macdonald, London. $285 \mathrm{pp}$.

Wiscombe, W.J. 1973: Solar radiation calculations for Arctic summer stratus conditions. Pp. 245-254 in Weller \& Bowling (eds.): Climate of the Arctic. Geoph. Inst., Univ. Alaska, Fairbanks.

Wyszecki, G. \& Stiles, W.S. 1982: Color science. (2nd ed.) John Wiley \& Sons, New York. 950 pp. 
